International Journal of Production Economics 187:53-67 · February 2017

DOI: 10.1016/j.j.jpe.2017.02.004

\title{
Joint supplier selection, production and replenishment of an unreliable manufacturing-oriented supply chain
}

\author{
$\underline{\text { Rached Hlioui }}^{\mathrm{a}}$, Ali Gharbi ${ }^{\mathrm{a}}$, Adnène Hajji ${ }^{\mathrm{b}}$ \\ ${ }^{a}$ Department of Automated Production Engineering, Production System and Control Laboratory, École de \\ technologie supérieure, University of Quebec, Montreal, QC, Canada \\ ${ }^{\mathrm{b}}$ Department of Operations and Decision Systems \& CIRRELT, Laval University, Quebec, QC, Canada
}

\begin{abstract}
:
Recent research suggests that short-term procurement is emerging as a powerful replenishment strategy, especially in a context where companies evolve in a rapidly changing market and many unforeseen events can force a quick update of supply needs. Being able to identify the optimal conditions under which a decision maker can choose one supplier over another, based on the whole system state, can help companies improve their productivity and control costs. This paper addresses this issue, and is intended to propose a control policy which coordinates supplier selection, replenishment, production and quality inspection decisions. We consider a manufacturing-oriented supply chain composed of multiple suppliers characterised by costs, delivery delays and quality that change randomly in time, and an unreliable manufacturer that operates in a dynamic stochastic context is considered. To solve this problem, a combination of mathematical formulation, simulation and optimization techniques has been adopted. Based on numerical examples and a sensitivity analysis, the results confirm the significant cost savings that our proposed dynamic supplier selection policy may ensure, as compared to a common long-term procurement strategy. Moreover, our extensive numerical examples demonstrate that under our proposed policy, considering more suppliers improves cost savings.
\end{abstract}

Keywords: Stochastic optimal control, Decision making, Sampling plan, Supplier selection, Production control, Simulation.

\section{Introduction}

Motivated by a practical reality and a large body of scientific literature that identifies supplier selection as a key factor in purchasing and supply management, we propose to 
integrate, in a stochastic and dynamic context, replenishment, production, quality control and supplier selection decisions for a manufacturing-oriented supply chain. To the best of the authors' knowledge, no existing work integrates all these aspects in a common framework. All decisions are assumed to occur at the manufacturer stage and made by a single decision maker who aims to minimise the total cost. Three selection criteria, namely, the supplier's product quality, delivery time and product price, which affect the total incurred cost, are considered. The quality of supplied items is an important criterion for a manufacturer, given that non-conforming raw material components would increase the quality cost. The replenishment cost criterion affects the purchasing cost. Finally, delivery time will affect the raw material stock and the continuity of the production process, which in turn influences the inventory and the shortage costs. To bring our problem closer to reality, we incorporate uncertainty into the supplier's parameters. Several factors may be at the root of such uncertainty: replenishment cost uncertainty could be caused by volatility of the raw materials market, while lead time uncertainty could be due to the complexity of procurement technology or transit damage; finally, supplier quality uncertainty could result from a deficient planned maintenance, an inadequate quality control procedure, or even transit damage.

From a supply chain integration perspective, in order to properly face supply uncertainty present when the supplier parameters are stochastic, the decision maker must not be limited to a single potential supplier. In fact, when the system is evolving under certain conditions (state), the supplier identified as the best, at a given moment, may not necessarily be the same for the next selection decision. Therefore, the selection decision must consider a pool of suppliers, and should be dynamic, allowing it to adjust replenishment decisions based on the whole system state and conditions offered by the potential suppliers. In this work, we propose a dynamic supplier selection policy coordinated with production, replenishment and quality control decisions. At any given time, the decision maker will select the supplier having the best offering, depending on the supplier parameters and the system state. When faced with a lack of raw materials and finished products, it is recommended to order from the supplier with the lowest delivery delay. Otherwise, if the level of finished products is comfortable, it will be better to order from the supplier with the lowest cost. Nevertheless, the effect of the quality of the 
delivered lot on the activities of the entire system must not be neglected. As a sampling plan is considered, a lot with low quality items faces an increase in its rejection frequency, and consequently, in its overall delivery delay. This shows the importance of considering these parameters simultaneously.

An experimental approach is used to model, simulate and optimize the policy. An indepth study is also conducted to illustrate the effectiveness of the proposed integrated strategy and its advantage, as compared to a selection policy that favours the selection of one suitable supplier from many potential candidates.

The rest of this paper is organised as follows. In section 2, an extended literature review is presented. In section 3, we present the usefulness of our work in practical contexts. In section 4, we present the notations used and a formulation of the integrated problem. In section 5, we propose a control policy for the system. We report a resolution approach in section 6 and a simulation model in section 7. In section 8, we give an example to present the numerical results. In section 9, we illustrate an extensive comparative study between different selection policies. In section 10, a practical implementation of the proposed policy is illustrated. Finally, the conclusion is given in section 11 .

\section{Literature review}

Over the years, several approaches and techniques have been developed to determine an effective supplier selection process. Chai et al. (2013) studied the decision making techniques in supplier selection for 123 international journal articles published between 2008 and 2012. The most frequently used, in order, are the analytic hierarchy process (AHP) (Chan et al., 2008), followed by linear programming (LP) (Lin et al., 2011), techniques for order preference by similarity to ideal solution (TOPSIS) (Liao and Kao, 2011), the analytic network process (ANP) (Lin et al., 2010), and data envelopment analysis (DEA) (Wu and Blackhurst, 2009).

Over the last two decades, a lot of attention has been directed at the coordination between procurement and inventory management or production planning for the development of supply chain management systems (Song et al, 2014). Recent papers and review papers 
(Aissaoui et al., 2007; Firouz et al., 2016; Tajbakhsh et al., 2007; Tang and Musa, 2011; Ware et al., 2014) have revealed the broad number of methods used to tackle this class of problem. Linear, goal and mixed-integer programming methods are the most common in a deterministic context. Stochastic programming and simulation-based approaches are the most common in a dynamic stochastic context. Due to the complexity of the integrated problem in a stochastic or dynamic context, only few papers have attempted to investigate it (Cui, 2014; Firouz et al., 2016). Chen and Zhang (2010) proposed a stochastic framework to determine the optimal production control policy and supplier selection procedure for a three-echelon supply chain. They proposed an improved analytical hierarchy process (AHP) to select the best supplier, where quality, service and the total cost under demand disruptions are considered. Keskin et al. (2010) developed a simulation-optimization-based approach to address a multiple-supplier, multiplewarehouse problem. They considered a trade-off between supplier selection and inventory decisions in the presence of stochastic demands. Their analysis revealed that in many cases, random demand influences inventory decisions, but not supplier selection decisions. Choudhary and Shankar (2013) integrated carrier selection, in addition to supplier selection and inventory decisions, in a dynamic model. Ventura et al. (2013) considered the same class of decisions in a multi-period, multi-stage serial supply chain with deterministic demand. In the same vein, Pazhani et al. (2016) implemented compartmentalized $(\mathrm{Q}, \mathrm{R})$ policies in a serial inventory system with supplier selection. In their analysis, they discussed the benefit of integrating inventory management with supplier selection decision. By building a stochastic dynamic programming model, Hajji et al. (2011a) presented an optimal strategy for an integrated replenishment, supplier selection and production control problem, where the quality of raw materials and finished products are assumed perfect. Naimi Sadigh et al. (2013) proposed a mathematical model to integrate supplier selection into production and distributor location decisions. Cui (2014) studied an integrated production planning and supplier selection problem for a manufacturer producing multiple products, where a new mathematical model was developed to maximize total manufacturer profits. Song et al. (2014) adopted a stochastic dynamic programming approach to study an integrated inventory management system for raw material procurement and production control in a manufacturing supply chain with 
multiple suppliers, in the presence of multiple uncertainties, such as uncertain material supplies, stochastic production duration and random customer demand. Sawik (2016) considered a bi-objective stochastic mixed-integer programming approach to integrate a supply, production and distribution scheduling problem under disruption risks. Burke et al. (2007) considered uncertain demand, supplier reliabilities and capacities within an integrated supplier selection and inventory allocation decision. They demonstrated that multiple sourcing always represents a better solution, except in cases where suppliers have very large capacities. Burke et al. (2009) extended their work to consider supply uncertainty and provided many insights into the impact of supply cost and reliability on the considered decisions. Other papers have focused their analysis within a contingency planning context (Ruiz-Torres et al. (2013)), or within limited global and local disruption scenarios (Sawik (2014)). Mendoza and Ventura (2012) considered quality and capacity factors for suppliers in models that integrate supplier selection and order quantity allocation. All these studies have shown that supplier selection must not be studied separately from the production or inventory management system. However, only a few of them include the quality of ordered items among the supplier selection criteria. Moreover, they do not consider any quality control strategy for the material upon reception.

In the supplier selection literature, the supplier's product quality is one of the three most frequently used criteria for selection (Lin and Kuo, 2014), the others being delivery time and cost (Ho et al., 2010; Sharma and Balan, 2013; Weber and Current, 1993). When the quality criterion is considered, only a few research works have integrated a raw material quality control policy into their study. To the best of our knowledge, a 100\% inspection policy is the most frequently adopted. For example, Rezaei and Davoodi (2008) presented a deterministic multi-item inventory model with supplier selection and imperfect quality, and where items of imperfect quality are sold in a single batch after a $100 \%$ inspection process. In the same vein, Gorji et al. (2014) coordinated order allocation, supplier selection and transportation decisions across a two-level supply chain with one retailer and a collection of suppliers. They took into account the relationship between quality imperfection and lot sizing, and assumed a 100\% inspection process upon reception. However, it has been shown that sampling plans improve the overall performance and can produce significant cost savings as compared to a $100 \%$ inspection policy, either for 
production control in a deteriorating manufacturing system (Bouslah et al., 2016a, b) or simultaneous production and supply control, where the raw material contains defectives (Hlioui et al., 2015b). Such sampling plans should therefore be considered upon reception of raw materials.

\section{Usefulness and practical context}

In their paper entitled "Short-term E-procurement strategies versus long-term contracts", Peleg et al. (2002) explained an emerging procurement strategy based on a short-term choice of suppliers. They cited many surveys conducted by influential groups and consulting firms (e.g., Aberdeen group, Deloitte) reporting that a short-term procurement strategy will constitute a significant part of the business practices of a large percentage of businesses. Based on costs and demand patterns, this study illustrated the influence of the parameters considered on the supply choice and the role short-term suppliers may play in any decision. In Cohen and Agrawal (1999), an analytical comparison of long- and shortterm supply contracts clearly showed that long-term contracts with one or many suppliers may not always be optimal. Recently, Federgruen and Yang (2014) addressed the problem of developing stationary strategies for replenishment with a general pool of suppliers. They particularly underlined the impact of quality supply risk (random yield factor) on a finite or infinite replenishment strategy involving many suppliers. All these research studies, as well as the others cited earlier, confirm the need for manufacturing firms to have adaptive replenishment strategies that consider the dynamic and stochastic nature of many parameters (costs, availability, demand, and quality). Moreover, the integrated nature of the decision making process of the considered system highly suggest a need to integrate this issue in the development process. For a manufacturing-oriented supply chain, our work will provide valuable insights for integrated strategies comprising supplier selection, replenishment, production and quality control. Recent papers, such as those by Firouz et al. (2016) and Amorim et al. (2016), as well as others cited herein, confirm the insights that our work can bring to the discourse. Although in Firouz et al. (2016), the problem addresses supplier selection and inventory control in a multisourcing distribution network, their work also shows that if the firm involved is a manufacturing one, it will be difficult to ignore the production stage. In Amorim et al. 
(2016), the integration of production, distribution and procurement decisions is assessed in the processed food industry. In this context, where the perishability of both raw materials and final products is a big issue, there is a clear need to integrate quality in an integrated decision framework. This issue was also recently reported in Mitra (2016), where the importance of sampling inspection and quality control decisions and their integration into replenishment and production decisions is outlined. Regarding sampling inspection, it has a long history of applications to various industries, most particularly in the food and electrical sectors.

Being able to identify the optimal conditions under which a decision maker can choose one supplier over another based on the whole system state can help companies improve their productivity and control costs. Another well-established reality confirms the insights of this work in the context of procurement from spot (open) markets. (Mahapatra et al., 2016) addressed this problem and reported that "the problem is of increasing significance with the emergence of electronic markets that facilitate procurement from competitive spot (open) markets. Models are developed to determine the optimal procurement policy in continuous time across the two sources for specified price and risk averse". Today, many web-based platforms and Enterprise Resource Planning (ERP) and Supply Chain Management (SCM) systems offer an integrated capacity to track many parameters of the whole system, including existing and potential suppliers, based on their cost and service level (quality and availability). Integrating the findings or the insights of the results obtained in a real case study may be considered in any extension of this work.

\section{Problem statement}

In this section, we present the notations used to develop the model and the problem statement.

\subsection{Notations}

The notations used in this paper are summarized as follows:

$$
\begin{aligned}
& A O Q \text { (.) : Average Outgoing Quality of non-conforming items in the raw } \\
& \text { material }
\end{aligned}
$$


$A O Q_{S O}($.$) : Average Outgoing Quality of non-conforming items in the raw$ material when supplier selection policy $S O$ is applied

$\mathrm{AOQ}_{\mathrm{SM}}($.$) : Average Outgoing Quality of non-conforming items in the raw$ material when supplier selection policy $S M$ is applied

pProd(.) : Proportion of non-conforming items produced by the manufacturing system

Dem : Finished product demand rate (units/time)

$\mathrm{u}^{\max } \quad$ : Maximum manufacturing production rate (units/time)

$Q \quad$ : Raw material lot size

n : Sample size

c : Acceptance number

$d \quad$ : Number of non-conforming raw material items in a sample

$l \quad:$ Number of suppliers

$s \quad$ : Raw material ordering point

$p^{j}($.$) \quad : Proportion of non-conforming items delivered from supplier j$

$\delta^{j}($.$) \quad : Replenishment delay to deliver a lot Q$ of raw materials from supplier $j$

$\tau_{\text {insp }} \quad:$ Inspection delay per unit (time/unit)

$\mathrm{W}^{\mathrm{j}} \quad$ : Ordering cost of supplier $j$

$\mathrm{CR}^{\mathrm{j}}($.$) \quad : Raw material cost from supplier j$ (\$/unit)

$\mathrm{C}_{\mathrm{R}}^{\mathrm{H}} \quad: \quad$ Raw material holding cost (\$/time/unit)

$c_{R F}^{\mathrm{T}} \quad:$ Cost of raw material transformation into finished product (\$/unit)

$c_{F}^{H} \quad:$ Finished product holding cost (\$/time/unit)

$c_{F}^{B} \quad:$ Finished product backlog cost (\$/time/unit)

$c_{\text {insp }} \quad:$ Raw material inspection cost (\$/unit)

$c_{N C}^{R} \quad:$ Non-conforming raw material acceptance cost (\$/unit)

\subsection{Problem statement}

We consider a three-stage supply chain involving multiple suppliers, a manufacturer producing one type of product and a final customer. An example of such a supply chain 
configuration is presented in Fig. 1. At each order, the manufacturer receives the raw material from a supplier in a lot of size $Q$. Each supplier $j$ is characterised by four parameters: a deterministic ordering cost $W^{j}$, a stochastic raw material purchasing cost $C R^{\mathrm{j}}\left(\right.$.) that follows a general probability distribution, a stochastic lead time $\delta^{j}($.$) that$ follows a general probability distribution, and a stochastic proportion $p^{j}($.$) of non-$ conforming items that also follows a general probability distribution. These probability distributions could be determined based on historical data collected on each supplier $j$. Raw materials are transformed at a production rate $u($.$) to finished products in order to$ respond to a continuous demand rate of the customer dem. The production rate $u($.$) can$ take a value between 0 and $U_{\max }$, where $U_{\max }$ denotes the maximum production rate. The production process could produce additional non-conforming products and the manufacturer could be unavailable due to failures (following a general time-to failure (TTF) distribution) and repair operations (following a general time-to-repair (TTR) distribution).

Upon reception, the manufacturer applies a simple lot-by-lot acceptance sampling plan with attributes. This plan is characterised by a random sample of size $n$ and an acceptance criterion $c$. Based on this inspection plan, if the number of non-conforming items $d$, found in this sample, is equal to or less than $c$, the lot will be accepted. The duration of this operation is equal to $n . \tau_{\text {insp }}$, where $\tau_{\text {insp }}$ is the inspection delay per unit. Otherwise, the lot will be refused and returned to its original supplier, and then a new order is placed. At this instant, the manufacturer is not obliged to keep the same supplier. He can choose any one that offers better replenishment conditions. By applying an acceptance sampling plan, some non-conforming products could pass through the inspection control. Therefore, all the non-conforming products sold to the customer are expected to be returned back to the manufacturer, who replaces them with good ones. 


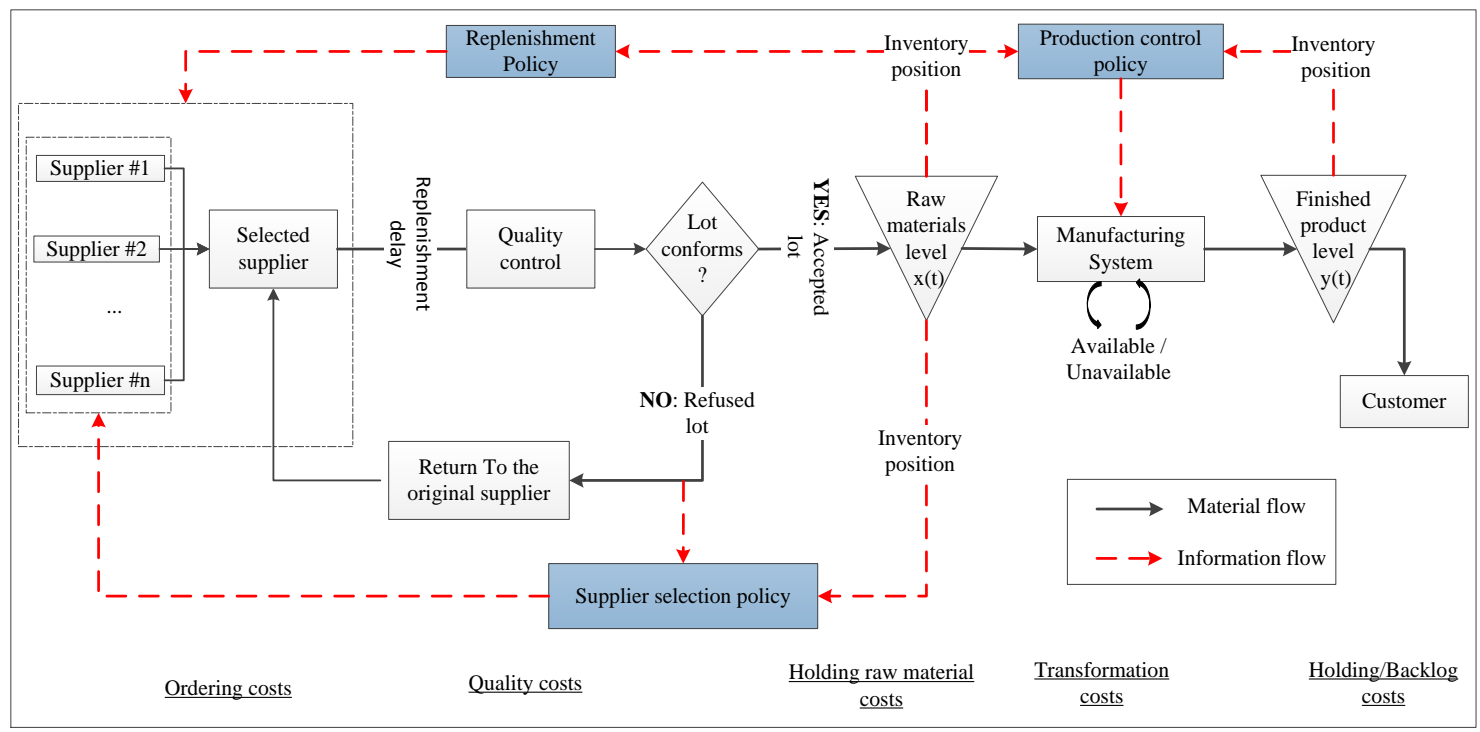

Fig. 1. System under study

Coordinating decisions along the entire chain is critical, since it requires determining carefully what to manufacture, as well as what, when and from whom to order. In this work, we aim to determine the best control policy for the integrated production, replenishment, supplier selection and quality control decisions that minimizes the incurred total cost, which includes inventory, backlog, inspection, replenishment and production costs. Two supplier selection policies are discussed and compared. In the first policy, named the $S O$ policy, the supplier selection decision consists in selecting and keeping the most suitable supplier from many potential candidates permanently. With the $S M$ policy however, all suppliers are considered as potential candidates, and the supplier selection decision may vary at any time, depending on suppliers' parameters and the whole system state.

\section{Problem formulation and structure of control policies}

\subsection{Problem formulation}

To formulate this problem, we used three components to define the state of the considered supply chain at time $t$ : 
- A discrete part $\alpha(t)$, which describes the state of the manufacturing system. A manufacturer is available when it is operational $(\alpha(t)=1)$ and unavailable during breakdowns $(\alpha(t)=2)$.

- A continuous part $y(t)$, which describes the cumulative surplus of the finished product. This part can be positive for an inventory or negative for a backlog.

- A piecewise continuous part $x(t)$, which describes the cumulative surplus level of the raw material. This part faces an impulsive upstream supply after a lot-by-lot sampling inspection and a downstream continuous demand (i.e., a manufacturing production rate $u()$.$) .$

The dynamics of the stock level $x(t)$ and $y(t)$ are given by the following differential equations:

$$
\begin{gathered}
\dot{y}(t)=u(t, \alpha)-\frac{D e m}{(1-A O Q(t)) \cdot(1-p \operatorname{Prod}(t))}, y(0)=y_{0} \quad \forall t \geq 0 \\
\left.\dot{x}(t)=-u(t, \alpha), x(0)=x_{0} \forall t \in\right] \xi_{i}, \xi_{i+1}[ \\
x\left(\xi_{i}^{+}\right)=x\left(\xi_{i}^{-}\right)+Q_{i} \forall i=1 \ldots N
\end{gathered}
$$

where $y_{0}, x_{0}$ denote the initial stock levels, Dem denotes the customer demand rate, $u(t, \alpha)$ denotes the manufacturing system production rate in mode $\alpha, A O Q(t)$ denotes the Average Outgoing Quality of non-conforming items in the raw material, $\operatorname{prrod}(\mathrm{t})$ denotes the proportion of non-conforming items produced by the manufacturing system, and $\xi_{i}^{-}, \xi_{i}^{+}$denote the negative and positive boundaries of the $N$ acceptance decision instants after a quality control operation, respectively.

\subsection{Structure of production, replenishment and quality control policies}

Several models have studied the integration of production and replenishment decisions for a supply chain in a stochastic dynamic context. Assuming raw materials with perfect quality, Hajji et al. (2011b) studied a multi-supplier, one-manufacturer, one-customer supply chain. In their study, the authors showed that a sub-optimal production policy and replenishment policy can be defined by a Hedging Point Policy (HPP) and an $(s, Q)$ policy, respectively. The HPP policy consists in building and maintaining a safety stock $Z_{P r}$ to face delays in supply operations, manufacturer repair operations and capacity 
shortage. The $(s, Q)$ consists in ordering an economic lot $Q$ of raw materials every time the raw material inventory level drops to a raw material safety stock $s$. Recently, Hlioui et al. (2015a, b) jointly considered a production, replenishment and sample inspection plan for raw materials quality control decisions for a one-supplier-manufacturer-customer supply chain. By considering an imperfect raw material quality, they showed that the production policy is controlled by a "Modified Hedging Point Policy" (MHPP), rather than the HPP policy. The replenishment policy is controlled by an $(s, Q)$ control policy. Concerning the quality policy, they studied a simple lot-by-lot acceptance plan with return or $100 \%$ inspection decision. Following our previous findings, we will present the considered production, replenishment and quality control policy in the next sub-sections.

\subsubsection{Production policy (MHPP)}

To control the production rate $u($.$) , the Modified Hedging Point Policy (MHPP) is$ applied, as in (Hlioui et al, 2015b). This policy allows us to take into consideration the proportion of non-conforming raw material items after a quality control $A O Q($.$) when the$ production rate is adjusted to follow the demand rate. However, unlike the aforementioned study, this proportion should take into account the different selected suppliers (Eq. 11) and the stochastic nature of the non-conforming proportion (Eq. 7 and Eq. 11). Herein, the MHPP is presented as follows:

$$
u(.)=\left\{\begin{array}{cl}
\mathrm{u}^{\max } & \text { if }\left(y(t)<Z_{P r}\right) \text { and }(x(t)>0) \\
& \text { and }(\alpha=1) \\
\frac{D e m}{(1-A O Q(t)) \cdot(1-\operatorname{PProd}(t))} & \text { if }\left(y(t)=Z_{P r}\right) \text { and }(x(t)>0) \text { and } \\
& (\alpha=1) \\
0 & \text {, otherwise. }
\end{array}\right.
$$

where: $U_{\max }$ denotes the maximum production rate and $Z_{P r}$ denotes the finished product hedging level for the production policy.

\subsubsection{Replenishment policy}

In a less general case, the $(s, Q)$ policy has been applied to control the replenishment decision for multi-supplier and perfect quality of raw materials (Hajji et al. (2011b) and 
one supplier and an imperfect raw material quality case (Hlioui et al., 2015b). This policy has shown a high level of effectiveness and a significant level of interaction with the other control parameters $\left(Z_{P r}, \ldots\right)$. Consequently, the choice of this policy seems well justified:

$$
(s, Q) \text { policy }\left\{\begin{array}{l}
\mathrm{Q} \text { if } \mathrm{x}(\mathrm{t}) \leq s, \mathrm{Q} \in \mathbb{N} \\
0, \text { otherwise. }
\end{array}\right.
$$

where: $s$ the ordering point and $Q$ the lot size.

\subsubsection{Quality control policy}

The lot-by-lot acceptance sampling plan is applied to control the quality of the delivered lot of raw materials. After the inspection of the lot, if it is refused, it will be returned to its original supplier, and then a new order is placed. As suppliers are characterised by stochastic parameters (cost, delivery and quality), the identified supplier to whom we return the refused lot may not be the most beneficial for us for the next selection decision. In this situation, and according to the system state, if there is another supplier with a better combination of cost, delay and quality criteria, it will be selected. The quality control policy is then presented as follows:

$$
\text { Quality Policy }\left\{\begin{array}{l}
\text { If } \mathrm{d} \leq \mathrm{c}, \text { lot is accepted and inspection is limited } \\
\text { to the sample } \mathrm{n} \\
\text { Otherwise, lot is returned to its supplier and } \\
\text { supplier selection policy (Eq. 10) must be } \\
\text { applied again. }
\end{array}\right.
$$

The probability of acceptance of the delivered lot from supplier $j P_{a}^{\mathrm{j}}\left(p^{j}(\mathrm{t})\right)$ can be calculated using the binomial probability distribution (Schilling and Neubauer, 2009) which is given as follows:

$$
P_{a}^{\mathrm{j}}\left(p^{j}(\mathrm{t})\right)=\sum_{d=0}^{c} \frac{n !}{d !(n-d) !}\left(p^{j}(\mathrm{t})\right)^{d}\left(1-p^{j}(\mathrm{t})\right)^{n-d}
$$




\subsection{Structure of supplier selection policy}

In this section, we present the two supplier selection policies.

\subsubsection{Most suitable supplier policy $(S O(j))$}

The $\mathrm{SO}(j)$ policy consists in choosing the most suitable supplier among all suppliers, and keeping him permanently. To determine his final preference (Fig. 2), the decision maker proceeds according to the following steps:

Step 0. Divide the main integrated problem (Fig. 1) into $l$ independent problems by considering one supplier at a time. Thus, when a supplier $j$ is considered, $A O Q_{S O(j)}($.$) can be calculated instantaneously as follows:$

$$
A O Q_{S O(j)}(t)=\frac{\sum_{i=1}^{N(t)}\left(p^{j}(\mathrm{t})\right)_{i} \cdot Q}{\sum_{i=1}^{N(t)} Q}
$$

where $N(t)$ represents the number of accepted inspected lots at time $t$ and $\left(p^{j}(\mathrm{t})\right)_{i}$ the proportion of non-conforming items at the $i^{\text {th }}$ accepted lot.

Step 1. Determine the total cost for each $l$ problems: $\operatorname{Cost}_{j}, j=1, \ldots, l$

Step 2. Optimize the total cost for each $l$ problems: $\operatorname{Cost}_{j}^{*}, j=1, \ldots, l$

Step 3. Select the supplier that returns the $\min \left(\operatorname{Cost}_{j}^{*}\right), j=1, \ldots, l$

where $\operatorname{Cost}_{j}^{*}$ represents the optimal total cost when the supplier $j$ is selected.

The optimization problem of the $S O(j)$ policy consists in finding the optimal values of the ordering point $s$, the lot size of raw materials $Q$, and the finished product hedging level $Z_{P r}$, that minimize the expected total incurred cost $(\operatorname{Cost}()$.$) . This cost includes: the$ ordering cost, the raw material cost, the raw material holding costs, the finished product holding/backlog costs, the transformation costs, the cost of sampling and the cost of replacing non-confirming products. 


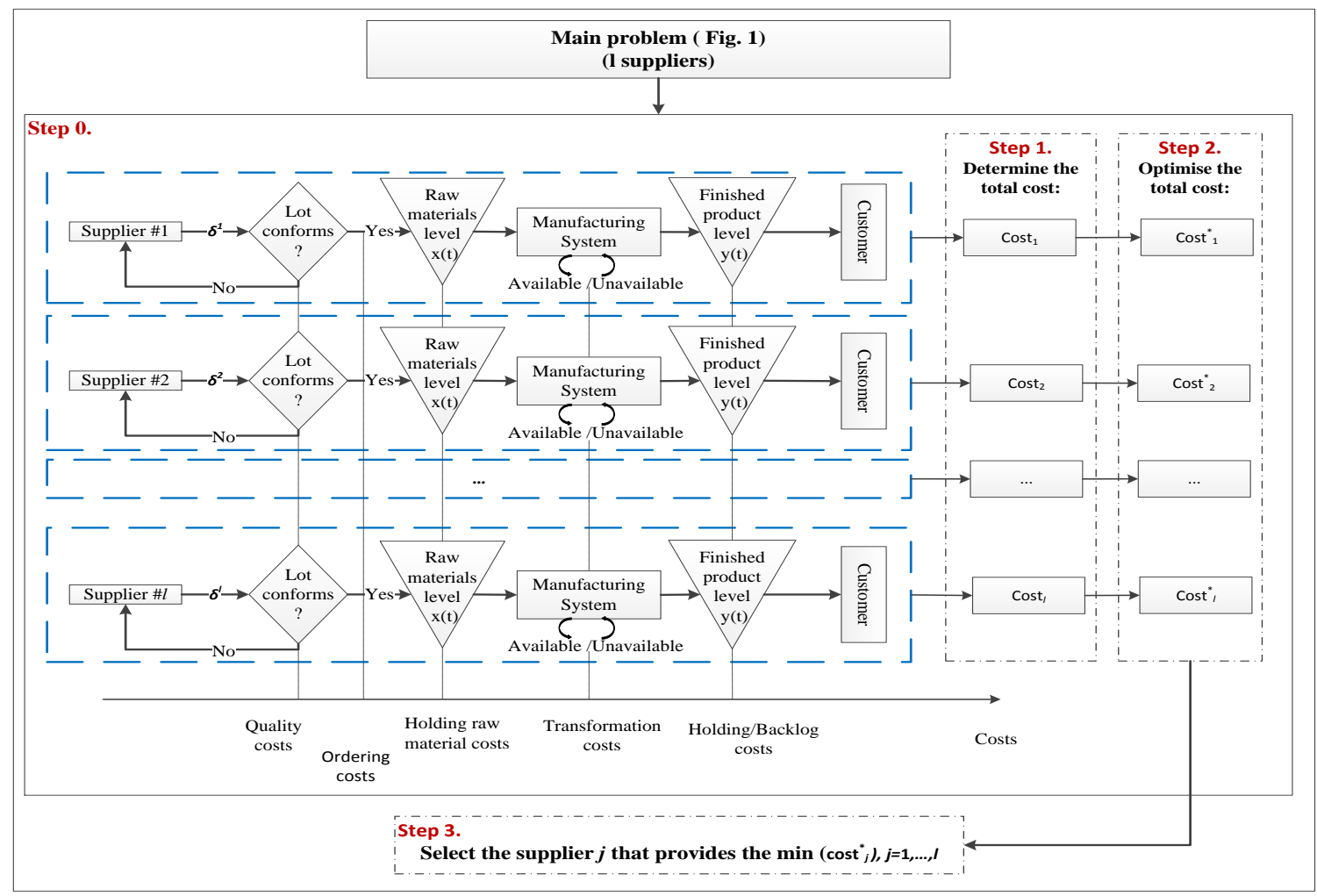

Fig. 2. Most suitable supplier selection methodology

\subsubsection{Dynamic supplier selection policy $(\operatorname{SM}(1,2, \ldots, l))$}

As shown in previous works (see sections 1,2 and 3), we argue that the whole supply chain will have an impact on the supplier selection decision. We present a new supplier selection policy which consists in dynamically selecting the best supplier by considering not only supplier' performances in terms of cost, delay and quality, but also by considering the system state (Inventory level of raw material and finished product).

Our policy is inspired from the control of a manufacturing system with adjustable capacity problems (Gharbi et al., 2011). In this work, authors showed that when there is a non-significant final stock level, the system may face a high risk of backlogs. Therefore, the manufacturing system adjusts its capacity to produce with two machines in order to avoid significant backlog costs, even if such a decision increases the production costs. When there is a significant final stock level, the system may face a lower risk of backlogs, and then the manufacturing system produces with only one machine to reduce the total production costs. 
In this work, as lot-by-lot acceptance plan is considered, the decision maker has to place an order of raw materials not only when the manufacturer needs to place an order to ensure enough raw materials for the production system, but also each time the delivered lot is refused after an inspection control (Fig. 3). At these two instances, the final stock level is an important indicator helping the decision maker selects the best supplier. Let $Z_{S}$ denote another finished product hedging level.

- If the finished product stock level is above $Z_{S}$, the decision maker considers that there is a comfortable quantity of final products. Then, it is better to reduce the total purchasing costs $\left(\min \left(C R^{j}(\mathrm{t})+\frac{W^{j}}{Q}\right)\right)$ (see Eq. 8). However, the decision maker must not neglect the effect of the frequency of rejection of a lot after a quality control exercise. A too high return frequency of a lot increases the overall delivery delay and the stock-out frequency of raw materials and final products. That is why we must reduce the frequency of return decisions by selecting the supplier with the maximum probability of acceptance $\left(\max \left(P_{a}^{j}\left(p^{j}(\mathrm{t})\right)\right)\right.$ or $\left.\min \left(\frac{1}{P_{a}^{j}\left(p^{j}(\mathrm{t})\right)}\right)\right)$. For these reasons, we must also consider the quality aspect of the delivered lot (see Eq. 8). In this situation, the supplier with the minimum $C Q^{j}(t)$ value must be selected, as this considers cost minimisation and quality maximisation simultaneously.

$$
C Q^{j}(t)=\frac{C R^{j}(t)+\frac{W^{j}}{Q}}{P_{a}^{j}\left(p^{j}(\mathrm{t})\right)}
$$

- When the finished product stock level is low (under the threshold $Z_{S}$ ), the decision maker needs to focus on the supplier that offers the fastest replenishment delay $\left(\operatorname{Min}\left(\delta^{j}(\mathrm{t})\right)\right)$ (see Eq. 9). This choice may increase the availability of the raw material and ensure continuity of the production process, thereby reducing the effect of backlog cost of the final product. However, a frequent return of lots increases the overall delivery delay and the stock-out frequency of raw materials. That is why we must also consider the quality aspect of the delivered lot (see Eq. 9). In this situation, the supplier with the minimum $D Q^{j}(t)$ value, which 
considers delay minimisation and quality maximisation simultaneously, must be selected.

$$
D Q^{j}(t)=\frac{\delta^{j}(t)}{P_{a}^{\mathrm{j}}\left(p^{j}(\mathrm{t})\right)}
$$

Eq. 8 and 9 are inspired from the Weighted Shortest Processing Time (WSPT) rule (Pinedo, 2002) for a single machine scheduling problems. In fact, the WSPT rule states that when a machine is available, the job having the smallest time $t_{i}$ and highest weight $\omega_{i}$ is selected based on the rule of $\min \left(\frac{t_{i}}{\omega_{i}}\right)$.

Then, the dynamic supplier selection $S M(1,2, \ldots, l)$ policy becomes:

$$
\begin{gathered}
S M(1,2, \ldots, l) \\
\quad \text { policy }
\end{gathered}\left\{\begin{array}{l}
\operatorname{Min}\left(C Q^{j}(t)\right), \text { if } x(t) \leq s \text { and } y(t) \geq \mathrm{Z}_{\mathrm{S}}, j=1, \ldots, l \\
\operatorname{Min}\left(D Q^{j}(t)\right), \text { if } x(t) \leq s \text { and } y(t)<\mathrm{Z}_{\mathrm{S}}, j=1, \ldots, l
\end{array}\right.
$$

where $\mathrm{Z}_{\mathrm{S}}$ is the finished product hedging level for the supplier selection policy, $\mathrm{Z}_{\mathrm{S}} \leq \mathrm{Z}_{\mathrm{Pr}}$ and $l$ is the total number of suppliers.

When the $\operatorname{SM}(1,2, \ldots, l)$ policy is applied, $\mathrm{AOQ}_{S M(1,2, \ldots, l)}($.$) can be calculated$ instantaneously as follows:

$$
\operatorname{AOQ}_{\mathrm{SM}(1,2, \ldots, l)}(\mathrm{t})=\frac{\sum_{\mathrm{i}=1}^{\mathrm{N}(\mathrm{t})}\left(p^{\lambda\left(H_{r e j}\right)}(t)\right)_{i} \cdot \mathrm{Q}}{\sum_{\mathrm{i}=1}^{\mathrm{N}(\mathrm{t})} \mathrm{Q}},
$$

where $N(t)$ represents the number of accepted inspected lots at time $t$ and $\left(\mathrm{p}^{\lambda\left(\mathrm{H}_{\mathrm{rej}}\right)}(\mathrm{t})\right)_{\mathrm{i}}$ represents the proportion of non-conforming items in the $\mathrm{i}^{\text {th }}$ accepted lot, delivered by the selected supplier $\lambda\left(\mathrm{H}_{\mathrm{rej}}\right)$ (see Fig. 3).

Fig. 3 illustrates the dynamic of $S M(1,2, \ldots, l)$ policy from the launch of a new order to its acceptance in the raw material stock. Furthermore, it shows the determination of the inspection costs depending on the number of rejection of a lot and the selected supplier. 


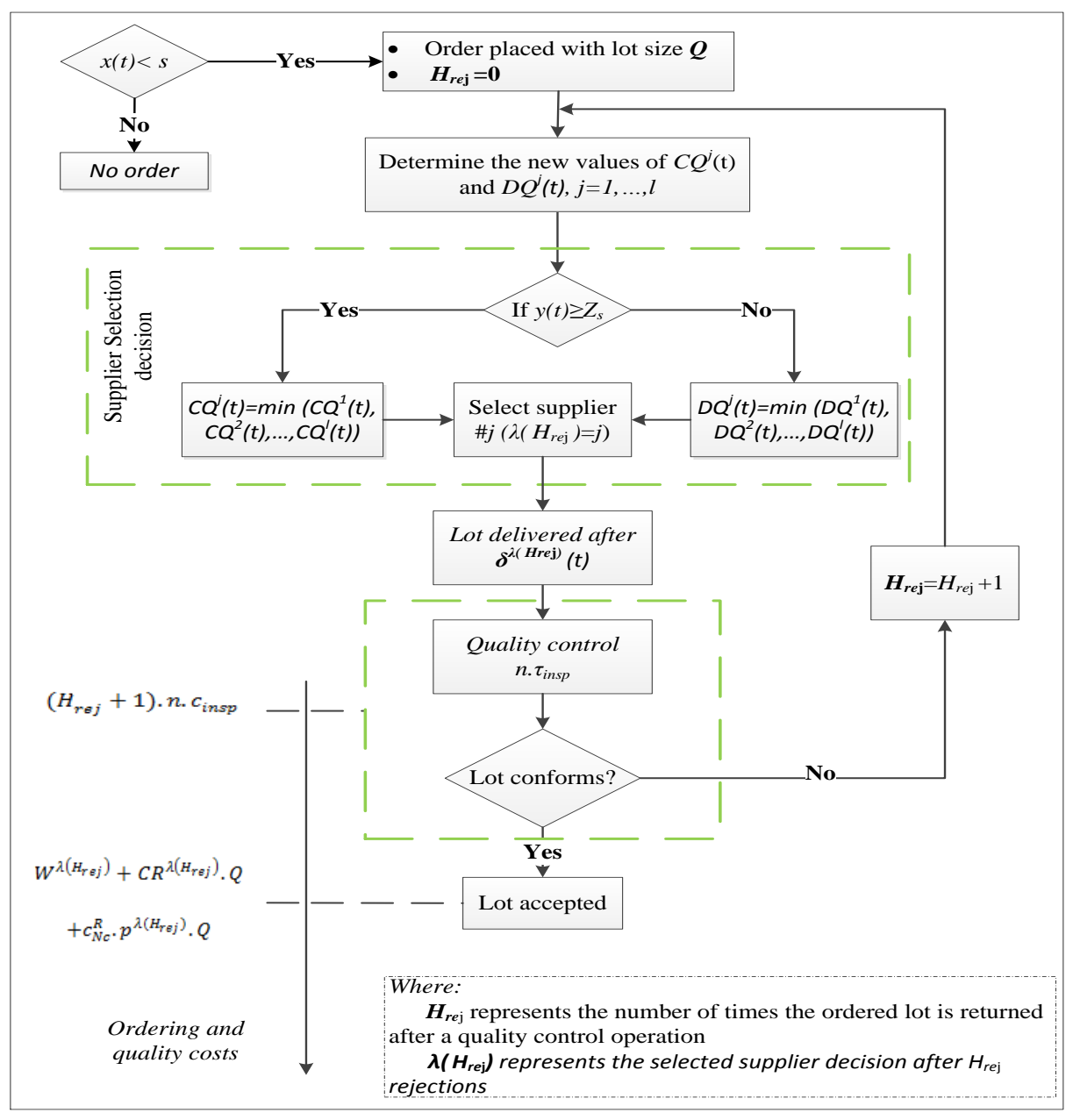

Fig. 3. Dynamic supplier selection methodology of $S M(1,2, \ldots, l)$ policy

The $S M(1,2, \ldots, l)$ policy decision variables are the ordering point $s$, the lot size of raw materials $Q$, the finished product hedging level for the production policy $Z_{P r}$ and the finished product hedging level for the supplier selection policy $Z_{S}$. The objective is to minimize the expected total incurred cost. This cost includes the average raw material holding cost, transformation costs, the finished product holding/backlog costs, the average ordering and quality costs.

\section{Resolution approach}

In this work, the optimization of the integrated production, replenishment, quality and supplier selection problems are subject to random lead time, random availability of the production system, random purchasing cost and random proportion of non-conforming 
items. The consideration of such an uncertain and dynamic context thus presents a significant challenge in terms of computing the costs function analytically. Moreover, the $S M$ policy is subject to higher variability caused by the supplier selection policy, which is a function of the finished product inventory level. In the case of a numerical approximation of a problem that is far less complicated than ours, Hajji et al. (2011b) reported the limits of the numerical resolution approach. For all these reasons, a simulation-optimization approach is used to experimentally determine the optimal control parameters that minimise the total incurred cost for the integrated decision problem. This approach is a combination of simulation modelling, experimental design and response surface methodology. The reader is referred to (Rivera-Gómez et al., 2013) and (Bouslah et al., 2016a) for more details. The main steps of this approach are as follows:

- Step 1- Description of the control policies: In this part, we formulate the considered manufacturing-oriented supply chain. The objective is to rigorously describe the dynamics of the system in terms of its states, and to define the different decision variables and the total incurred cost function to be minimized. Next, the structure of the integrated production, replenishment, supplier selection and quality control policies are developed, as shown in section 3 .

- Step 2- Simulation model: A discrete/continuous simulation model is developed to reproduce the dynamics of the problem. This model is developed using the SIMAN simulation language with $\mathrm{C}++$ subroutines (Pegden, 1995). In fact, such a combination reduces the total execution time (Lavoie et al., 2010) and accurately models the impulsecontinuous nature of the supply-production-inventory dynamic. In this step, the control policy parameters (also called design factors) $\left(s, Q, Z_{P r}\right.$ and $\left.Z_{S}\right)$ are considered as input and the total incurred cost as output of the model.

- Step 3- Cost function estimation and Optimization: This step includes three substeps. First, an appropriate experimental design is determined to define the number of experiments, the experimental space of the independent variables, and the variation extent of each design factor. Second, an analysis of variance (i.e., ANOVA) is carried out to determine the effects of the main factors, their quadratic effects, and their interactions that have a significant effect on the total cost. Finally, the Response Surface Methodology is used to determine the relationship between the significant main factors 
and interactions and the incurred total cost. Then, the model is optimized in order to determine the optimal values of the design factors and optimal total cost.

\section{Validation of the simulation model}

To reproduce the dynamic behaviour of the considered supply chain, a simulation model is developed and executed through the ARENA simulation software.

Fig. 4 shows the dynamic variation of the raw material and finished product stock and the system parameters according to the $\operatorname{SM}(1,2)$ control policy $(l=2)$. When the production system is unavailable (arrow (1)) or raw material is out of stock $(x(t)=0$ ) (arrow (2), the transformation process is stopped. When the production system is available and the raw material level $x(t)>0$, the system transforms the raw material into a finished product. This transformation is ensured with a production rate equal to the maximal rate whenever the finished product $y(t)$ is below $Z_{P r}$ (arrow (3)) and at an adjusted demand rate whenever $y(t)$ is equal to $Z_{P r}$ (arrow (4)). The production process leads to a decrease in the raw material levels across time. When the $x(t)$ level crosses the ordering point, the decision maker orders a new lot (arrow (5)). Faced with two suppliers having stochastic parameters, the decision maker has to check the $y(t)$ level. If $y(t) \geq Z_{S}$ (arrow (6)), the supplier selection decision will be based on the $\operatorname{Min} C Q^{j}(t)$ condition (given that $C Q^{1}\left(t_{1}\right)>C Q^{2}\left(t_{1}\right)$, supplier 2 must be selected (arrow (7)). Otherwise, if $y(t)<$ $Z_{S}$ (arrow ${ }^{8}$ ), the supplier selection decision will be based on the $\operatorname{Min} D Q^{j}(t)$ condition (given that $D Q^{1}\left(t_{3}\right)<D Q^{2}\left(t_{3}\right)$, supplier 1 must be selected (arrow (9)). Upon the lot being delivered (arrow (10), a sample of size $n$ is inspected with A delay. If the lot is accepted (arrow (11), it is added to the $x(t)$ stock, where an impulsive increase in $\mathrm{Q}$ items is observed (arrow (12). If the lot is refused (arrow (13), the lot is returned to its original supplier. Based on level $y(t)$ and the supplier selection policy, the order is placed with the corresponding supplier and the manufacturer must wait for an additional lead time. As $y(t) \geq \mathrm{Z}_{\mathrm{S}}$ (arrow ${ }^{14}$ ), the supplier selection decision will be based on the $\operatorname{Min} C Q^{j}(t)$ condition (given that $C Q^{1}\left(t_{2}\right)<C Q^{2}\left(t_{2}\right)$, supplier 1 must be selected (arrow $\left.{ }^{15}\right)$ ). Such 
an additional waiting delay may increase the risk of the out-of-stock of raw material and leads to a backlog of finished products (arrow (16)).

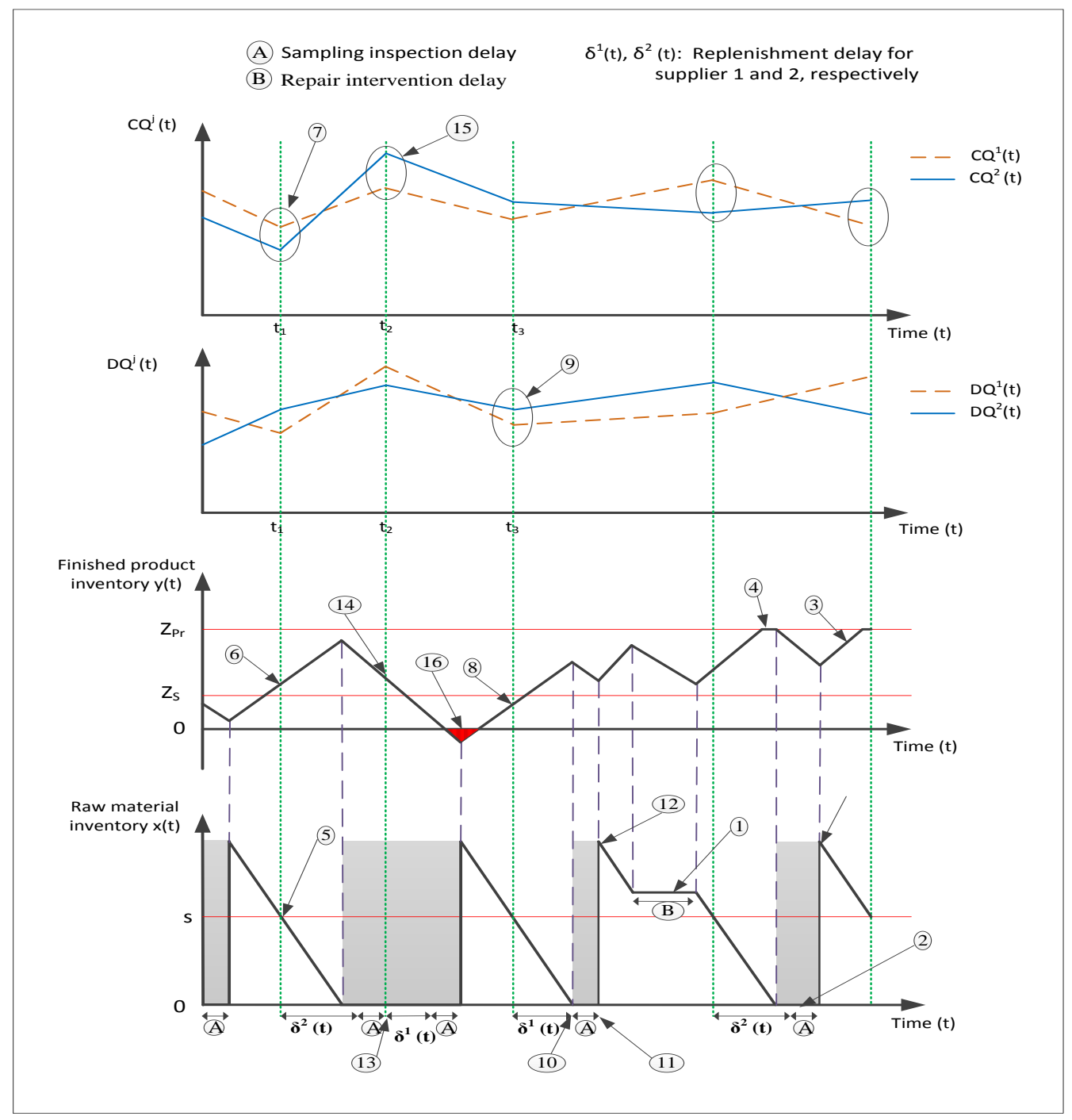

Fig. 4. Dynamic variation of stocks and system parameters $($ Case $\mathrm{l}=2$ )

\section{Experimental design and Response Surface Methodology}

This section first introduces the results of a basic example to illustrate the resolution approach. Then, we conduct a sensitivity analysis to highlight the robustness of our approach. For illustration purposes, two suppliers are considered in this example. The characteristics of the supply chain and the suppliers are presented in Table 1-3, respectively. In this example, we note by $S O(1)$ the integrated control policy where only 
supplier 1 is selected; $S O(2)$ represents the integrated control policy where only supplier 2 is selected and, $\operatorname{SM}(1,2)$ the policy where both suppliers 1 and 2 are considered using the dynamic supplier selection policy.

Table 1 Inspection and cost parameters

\begin{tabular}{cccccccccccc}
\hline Parameter & $u^{\max }$ & $\operatorname{dem}$ & $n$ & $\mathrm{c}$ & $c_{R}^{H}$ & $c_{R F}^{T}$ & $c_{\text {insp }}$ & $c_{F}^{H}$ & $c_{F}^{B}$ & $c_{\text {remp }}^{F}$ & $\tau_{\text {insp }}$ \\
\hline Values & 480 & 310 & 100 & 3 & 1 & 2 & 50 & 1 & 16 & 100 & $5.10^{-4}$
\end{tabular}

Table 2 Production parameters

\begin{tabular}{cccc}
\hline Parameter & TTF & TTR & pProd \\
\hline Values & Expo (15) & Expo (1.65) & 0
\end{tabular}

Table 3 Supplier parameters

\begin{tabular}{ccccc}
\hline Parameter & $\mathrm{W}^{\mathrm{j}}(\$)$ & $\mathrm{CR}^{\mathrm{j}}().(\$)$ & $\delta^{\mathrm{j}}().($ time $)$ & $\mathrm{p}^{\mathrm{j}}()$. \\
\hline Supplier 1 & 4000 & $U(2,7)$ & $U(1.5,3)$ & $U(2.3 \%, 2.7 \%)$ \\
Supplier 2 & 4000 & $U(6,10)$ & $U(1,2.5)$ & $U(1.8 \%, 2.2 \%)$
\end{tabular}

where $\operatorname{Expo}(x)$ denotes the exponential probability distribution of mean $x$, and $U(a, b)$ denotes the uniform probability distribution defined by the two parameters $a$ and $b$.

\subsection{Experimental results}

Depending on the number of independent variables, simulation runs were conducted according to a complete $3^{3}$ design of experiments for both $S O(1)$ and $S O(2)$ policies (as there are only three independent variables, namely, $s, Q$ and $Z_{P r}$ ) and according to a Face-centered Central Composite design (FCCD) $\left(2^{4}+8\right.$ star points +3 center points) for the $S M(1,2)$ policy (as there are four variables, namely, $s, \mathrm{Q}$ and $Z_{P r}$ and $Z_{S}$ ). In fact, when the number of variables is higher than three, the central composite plan is preferred thanks to its two main characteristics: orthogonality and rotatibility (Lavoie et al., 2010). For more details, we refer the reader to Montgomery (2013). 
Based on statistical analysis (See Appendix A), the second-order models of the total cost for each supplier selection policy are given by:

$$
\begin{aligned}
& \operatorname{Cost}_{S O(1)}\left(s, Q, Z_{P r}\right)=23747.8-9.64915 . s-3.32566 . Q- \\
& 6.05421 . Z_{P r}+0.00165435 . s^{2}+0.000898732 . s . Q+ \\
& 0.00168961 . s . Z_{P r}+0.000252075 . Q^{2}+0.00038271 . Q . Z_{P r}+ \\
& 0.000846585 . Z_{P r}^{2} . \\
& \operatorname{Cost}_{S O(2)}\left(s, Q, Z_{P r}\right)=14460.7-4.41983 . s-1.20931 . Q- \\
& 4.03709 . Z_{P r}+0.00129339 . s^{2}+0.000350057 . s . Q+ \\
& 0.000955228 . s . Z_{P r}+0.000128105 . Q^{2}+0.000126277 . Q . Z_{P r}+ \\
& 0.00101796 . Z_{P r}^{2} . \\
& \operatorname{Cost}_{S M(1,2)}\left(s, Q, Z_{P r}, \beta\right)=16626.3-6.62899 . s-1.98496 . Q- \\
& \text { 3.72058. } Z_{P r}-1308.02 . \beta+0.00151203 . s^{2}+0.000696086 . s . Q+ \\
& 0.00088215 . s . Z_{P r}+0.573627 . s . \beta+0.000170112 . Q^{2}+ \\
& 0.000118853 . Q . Z_{P r}+0.143787 . Q \cdot \beta+0.000817744 . Z_{P r}^{2}+ \\
& 0.120883 . Z_{P r} \cdot \beta+234.618 \beta^{2} .
\end{aligned}
$$

Fig. 5 presents the projection of the cost response surfaces on different two-dimensional plan. Fig. 5 shows the parameter corresponding to the minimum total cost respectively for the $S O(1), S O(2)$ and $S M(1,2)$ models: $s^{*}=1205.97, Q^{*}=3193$ and $Z_{P r}^{*}=1694.56$ (Fig. 5.(a)); $s^{*}=780.25, Q^{*}=2947$ and $Z_{P r}^{*}=1434.16$ (Fig. 5.(b)) and $s^{*}=956.08, Q^{*}=$ 3239, $Z_{P r}^{*}=1502.09$ and $Z_{S}^{*}=343.28$ (Fig. 5.(c)).

To validate each second order model, a cross-check on each optimal solution is performed. We therefore conducted 20 extra replications using optimal parameters (Table 4) and determined the different confidence intervals at 95\% (Eq. 15). The results in Table 4 show that the optimal cost of each model is within the confidence interval.

$$
\bar{C}^{*}(h) \pm t \frac{\sigma}{2}, \boldsymbol{h - 1} \cdot \sqrt{S^{2}(h) / h}
$$


where $\bar{C}^{*}$ is the average optimal cost, $S$ the sample standard deviation, $h$ the number of replication, and $(1-\sigma)$ the confidence level.

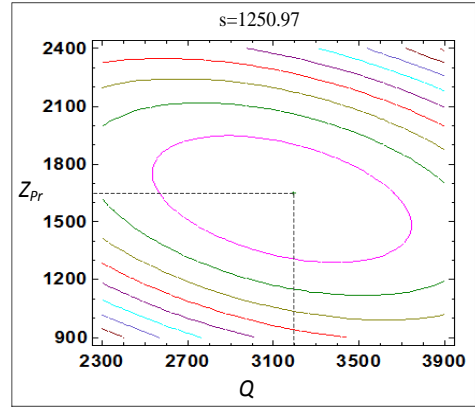

(a) $S O(1)$ policy

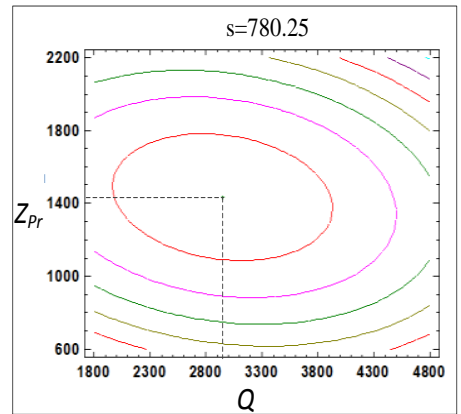

(b) $S O(2)$ policy

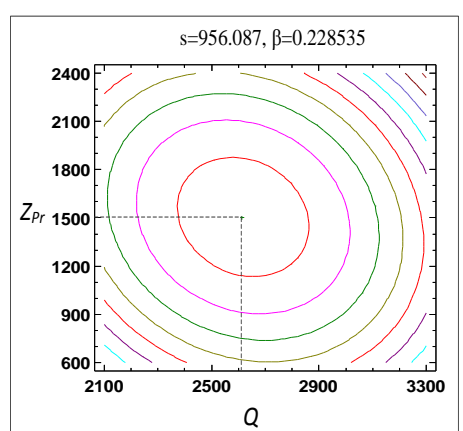

(c) $\operatorname{SM}(1,2)$ policy

Fig. 5. Contours of Estimated Response Surface

Table 4 Confidence interval and optimal variables and cost results

\begin{tabular}{|c|c|c|c|c|c|c|}
\hline \multirow{2}{*}{ Policies } & \multicolumn{4}{|c|}{ Optimal variables } & \multicolumn{2}{|c|}{ Optimal cost } \\
\hline & $s^{*}$ & $Q^{*}$ & $Z_{P r}^{*}$ & $Z_{S}^{*}$ & Cost $^{*}$ & CI $(95 \%)$ \\
\hline \multirow{2}{*}{$S O(1)$} & 1205.9 & \multirow{2}{*}{3193} & 1650.5 & \multirow[b]{2}{*}{ - } & \multirow{2}{*}{7622.82} & \multirow{2}{*}[7617.89,7657.12]{} \\
\hline & 7 & & 3 & & & \\
\hline \multirow{2}{*}{$S O(2)$} & \multirow{2}{*}{780.25} & \multirow{2}{*}{2947} & 1434.1 & \multirow[b]{2}{*}{-} & \multirow{2}{*}{8059.72} & \multirow{2}{*}[8056.24,8086.22]{} \\
\hline & & & 6 & & & \\
\hline \multirow{2}{*}{$\operatorname{SM}(1,2)$} & \multirow{2}{*}{956.08} & \multirow{2}{*}{3239} & 1502.0 & \multirow{2}{*}{343.28} & \multirow{2}{*}{7269.57} & \multirow{2}{*}[7260.98,7287.84]{} \\
\hline & & & 9 & & & \\
\hline
\end{tabular}

The results in Table 4 allow us to draw two conclusions. The first concerns the choice among suppliers. We see that the decision maker should select supplier 1 rather than supplier 2. The second concerns the choice of the supplier selection policy. Table 4 shows that the $S M(1,2)$ policy is the best one. Such result was expected. In fact, thanks to the flexibility of the $\operatorname{SM}(1,2)$ policy, the decision maker could, at any time, select the supplier with the best offering, depending on the supplier parameters and the system state. To illustrate the robustness of this resolution approach for ranges of systems parameters, a sensitivity analysis will be performed. 


\subsection{Sensitivity analysis}

The objective of this analysis is to show the robustness of our resolution approach. By changing one operational parameter at a time, we analyse the impact of this variation on the optimal design factors $\left(s^{*}, Q^{*}, Z_{P r}^{*}, Z_{S}^{*}\right)$ and incurred cost $\left(\right.$ Cost $\left.^{*}\right)$.

Table 5 presents the results of this sensitivity analysis compared to the basic case, when a $S M(1,2)$ policy is considered. This analysis is also performed on both $S O(1)$ and $S O(2)$. For readability, Table 5 illustrates only the optimal expected total cost of the $S O(1)$ and $S O(2)$ policies. 
Table 5 Sensitivity analysis data and results of the $\operatorname{SM}(1,2)$ policy

\begin{tabular}{|c|c|c|c|c|c|c|c|c|c|c|c|c|}
\hline \multirow{2}{*}{ Cases } & \multirow{2}{*}{ Parameter } & \multirow{2}{*}{ Variation } & \multicolumn{4}{|c|}{ Optimal Parameters } & \multirow{2}{*}{$T C Q$} & \multirow{2}{*}{$T D Q$} & \multirow{2}{*}{$\operatorname{Cost}_{S M(1,2)}^{*}$} & \multirow{2}{*}{$\operatorname{Cost}_{S O(1)}^{*}$} & \multirow{2}{*}{$\operatorname{Cost}_{S O(2)}^{*}$} & \multirow{2}{*}{$\begin{array}{c}\text { Impact on } \\
\operatorname{SM}(1,2) \text { policy }\end{array}$} \\
\hline & & & $s^{*}$ & $Q^{*}$ & $Z_{P r}^{*}$ & $Z_{S}^{*}$ & & & & & & \\
\hline Base & - & - & 956.08 & 3239 & 1502.09 & 343.28 & $91.41 \%$ & $8.59 \%$ & 7269.57 & 7622.82 & 8058.72 & - \\
\hline \multirow{2}{*}{1} & \multirow{2}{*}{$c_{R}^{H}$} & 1.2 & 911.44 & 3009 & 1548.83 & 561.52 & $88.28 \%$ & $11.72 \%$ & 7609.5 & 7981.38 & 8362.12 & $s^{*} \downarrow Q^{*} \downarrow Z_{P r}^{*} \uparrow Z_{S}^{*} \uparrow \operatorname{Cost} t^{*} \uparrow$ \\
\hline & & 0.8 & 996.96 & 3563 & 1481.09 & 218.36 & $93.22 \%$ & $6.78 \%$ & 6908.59 & 7235.84 & 7715.01 & $s^{*} \uparrow Q^{*} \uparrow Z_{P r}^{*} \downarrow Z_{S}^{*} \downarrow \operatorname{Cos} t^{*} \downarrow$ \\
\hline \multirow{2}{*}{2} & \multirow{2}{*}{$c_{F}^{H}$} & 1.2 & 1000.4 & 3194 & 1377.11 & 285.90 & $90.8 \%$ & $9.2 \%$ & 7499.65 & 7875.75 & 8288.78 & $S^{*} \uparrow Q^{*} \downarrow Z_{P r}^{*} \downarrow Z_{S}^{*} \downarrow \operatorname{Cos} t^{*} \uparrow$ \\
\hline & & 0.8 & 933.4 & 3280 & 1627.93 & 410.57 & $91.78 \%$ & $8.22 \%$ & 7017.59 & 7342.15 & 7812.09 & $s^{*} \downarrow Q^{*} \uparrow Z_{P r}^{*} \uparrow Z_{S}^{*} \uparrow \operatorname{Cos} t^{*} \downarrow$ \\
\hline \multirow{2}{*}{3} & \multirow{2}{*}{$c_{F}^{B}$} & 18 & 990.94 & 3233 & 1545.87 & 408.35 & $91.86 \%$ & $8.14 \%$ & 7340.19 & 7710.07 & 8126.72 & $s^{*} \uparrow Q^{*} \downarrow Z_{P r}^{*} \uparrow Z_{S}^{*} \uparrow \operatorname{Cos} t^{*} \uparrow$ \\
\hline & & 14 & 925.56 & 3248 & 1451.68 & 282.58 & $91.22 \%$ & $8.78 \%$ & 7187.75 & 7526.01 & 7980.63 & $s^{*} \downarrow Q^{*} \uparrow Z_{P r}^{*} \downarrow Z_{S}^{*} \downarrow$ Cost* $t^{*}$ \\
\hline \multirow{2}{*}{4} & \multirow{2}{*}{$c_{N C}^{R}$} & 150 & 957.05 & 3229 & 1502.61 & 408.52 & $90.72 \%$ & $9.28 \%$ & 7651.02 & 8020.24 & 8376.03 & $S^{*} \uparrow Q^{*} \downarrow Z_{P r}^{*} \uparrow Z_{S}^{*} \uparrow \operatorname{Cos} t^{*} \uparrow$ \\
\hline & & $\mathbf{5 0}$ & 972.42 & 3247 & 1501.69 & 284.25 & $92.14 \%$ & $7.86 \%$ & 6887.48 & 7225.4 & 7743.4 & $S^{*} \downarrow Q^{*} \uparrow Z_{P r}^{*} \downarrow Z_{S}^{*} \downarrow$ Cost* $\downarrow$ \\
\hline \multirow{2}{*}{5} & \multirow{2}{*}{$n$} & 130 & 1112.88 & 3515 & 1769.37 & 979.53 & $80.95 \%$ & $19.05 \%$ & 7762.61 & 8718.81 & 8264.64 & $s^{*} \uparrow Q^{*} \uparrow Z_{P r}^{*} \uparrow Z_{S}^{*} \uparrow \operatorname{Cos} t^{*} \uparrow$ \\
\hline & & 70 & 770.452 & 2651 & 1414.77 & 275.00 & $92.42 \%$ & $7.58 \%$ & 6756.83 & 6998.74 & 7525.9 & $s^{*} \downarrow Q^{*} \downarrow Z_{P r}^{*} \downarrow Z_{S}^{*} \downarrow \operatorname{Cos} t^{*} \downarrow$ \\
\hline
\end{tabular}

where: $T C Q$ (resp. $T D Q$ ) represents the percentage of time $\min (C Q)$ objective (resp. $\min (D Q)$ objective) that was considered in the case of $\operatorname{SM}(1,2)$ policy. 
- Variation of the raw material holding cost $c_{R}^{H}$ (case 1): Increasing $c_{R}^{H}$ results in a tendency to decrease the raw material stock level to avoid further inventory costs $\left(s^{*}\right.$ and $Q^{*}$ decrease). However, by keeping a lower level of raw material, the stock-out frequency of raw materials may increase. Consequently, the system increases the finished product threshold $Z_{P r}^{*}$ and the finished product threshold for supplier selection policy $Z_{S}^{*}$ to avoid shortage. Increasing $Z_{P r}^{*}$ enables a faster response to continuous demand. Increasing $Z_{S}^{*}$ aims to speed up the arrival of raw materials and to reduce the effect of lead time (TDQ increases) when a lot is refused. Decreasing $c_{R}^{H}$ leads to an opposite variation of the optimal parameters.

- Variation of the finished product holding $\operatorname{cost} c_{F}^{H}$ (case 2): Increasing $c_{F}^{H}$ results in a tendency to decrease the optimal finished product threshold level $Z_{P r}^{*}$ to avoid further inventory costs. Consequently, $S^{*}$ increases and $Q^{*}$ decreases, leading to more frequent orders with lower lot sizes in order to reduce the stock-out frequency of raw materials. $Z_{S}^{*}$ decreases to reduce the effect of purchasing costs. The variation of $s^{*}$ and $Q^{*}$ increases the frequency of application of the supplier selection decision. As the frequency of a return decision after a quality control may increase, the system also tries to select the best supplier in terms of delay (TDQ increases). Decreasing $c_{F}^{H}$ leads to an opposite variation of the optimal parameters.

- Variation of the finished product backlog $\operatorname{cost} c_{F}^{B}$ (case 3): Increasing $c_{F}^{B}$ results in a tendency to increase the optimal threshold $Z_{P r}^{*}$ to ensure better protection against shortages. Consequently, $s^{*}$ increases and $Q^{*}$ decreases, leading to more frequent orders, with lower lot sizes. $Z_{S}^{*}$ increases to reduce the effect of lead time when a lot is refused in order to ensure the continuity of the production process. At the same time, the variation of $S^{*}$ and $Q^{*}$ increases the frequency of application of the supplier selection decision. For these reasons, the system also tries to select the best supplier in terms of costs (TCQ increases) in order to reduce the effect of purchasing costs. Decreasing $c_{F}^{H}$ leads to an opposite variation of the optimal parameters.

- Variation of the non-conforming raw material acceptance cost $c_{N c}^{R}$ (case 4): Increasing $c_{N C}^{R}$ results in a tendency to increase $s^{*}$ and decrease $Q^{*}$ leading to more frequent orders, with lower lot sizes. This variation aims to increase the frequency of application of the supplier selection decision, as he looks to select, at each time, the 
best supplier in terms of quality, in order to reduce the proportion of non-confirming delivered items, and to then avoid further non-conforming acceptance costs. Consequently, $Z_{S}^{*}$ increases in order to reduce the effect of lead time when a lot is refused to ensure the continuity of the production operation by reducing the stock-out frequency of raw materials ( $T D Q$ increases). $Z_{P r}^{*}$ increases to ensure there is enough finished product to meet continuous demand. Decreasing $c_{N C}^{R}$ leads to an opposite variation of the optimal parameters.

- Variation of the sample size $n$ (case 5): Increasing $n$ results in a tendency to increase the lot rejection probability $(1-P a)$, and then to an increase in raw material stock-out frequency. Consequently, $s^{*}$ and $Q^{*}$ increase in order to ensure that the raw material is available, $Z_{P r}^{*}$ increases to tackle the raw material stock-out frequency and demand, and $Z_{S}^{*}$ increases to reduce the total lead time (TDQ increases) when a lot is refused. Decreasing $n$ leads to an opposite variation of the optimal parameters.

As expected, the results obtained in this analysis make sense. We can confirm that varying the control parameters evolves as expected with respect to parameter variations. The results also illustrate the advantage of the new developed SM policy. As obtained in Table 4, Table 5 shows that the SM policy always guarantees the best cost compared to the $S O$ policy.

Depending on the parameters, the $S O(1)$ policy seems to be preferable to the $S O(2)$ policy almost everywhere except for case 5 (Table $5, n=130$ ). Hence, to conclude this issue of selecting the best supplier selection policy, we conduct an in-depth comparative study between all the supplier selection policies in the next section.

\section{Extensive study}

Additional experiments were conducted to determine the decision maker preference to the best supplier selection policy. We first investigate the decision maker choice for a wide range of system parameters in the case of two suppliers. Secondly, we study the decision maker preference in the case of three suppliers. Then, we consider the case of more complex system. 


\subsection{Case of two suppliers}

In this section, we extend the base case study to a wide range of system parameters. To establish different curves, and then carry out comparisons between the supplier selection policies in the case of two suppliers, we vary the parameters of one supplier at a time. In this study, we present the results after the variation of the parameters of supplier 1. Fig. 6 illustrates the variation of the optimal total cost depending on the quality of the delivered lot for different inspection plan severities. Fig. 7 illustrates the variation of the optimal total cost depending on the replenishment delay. Fig. 8 illustrates the variation of the optimal total cost depending on raw material cost. To improve the readability of the figures, we present only the mean value of the uniform probability distribution $U(a, b)$ while keeping the same $(b-a)$ variation for the different studied parameters.

\subsubsection{Effect of non-conforming proportion variation and sampling plan severity}

From Fig. 6, we note that when an $S O$ policy is applied, the decision maker may select supplier 1 or supplier 2, depending on the supply chain parameters. Fig. 6 shows the existence of a switching point $S P_{Q}$, which represents the maximum mean value of $p^{1}$ for which supplier 1 is preferred. Exceeding this value, the decision maker must change his preference to supplier 2. In addition, Fig. 6 illustrates an interesting point concerning the effect of the sampling plan severity. It can be seen that when the sampling plan is tighter, the switching point value decreases from $3.3 \%$ (Fig. 6.b) to $2.85 \%$ (Fig. 6.a) to $2.35 \%$ (Fig. 6.c). Indeed, if the sampling plan is more severe, the decision maker selection changes from supplier 1 to supplier 2 much earlier when supplier 1's quality deteriorates (which makes sense). Concerning the choice of the supplier selection policy, Fig. 6 shows that for all cases, the $S M(1,2)$ policy is always preferred to the $S O$ policy $(S O(1)$ and $S O(2))$. 


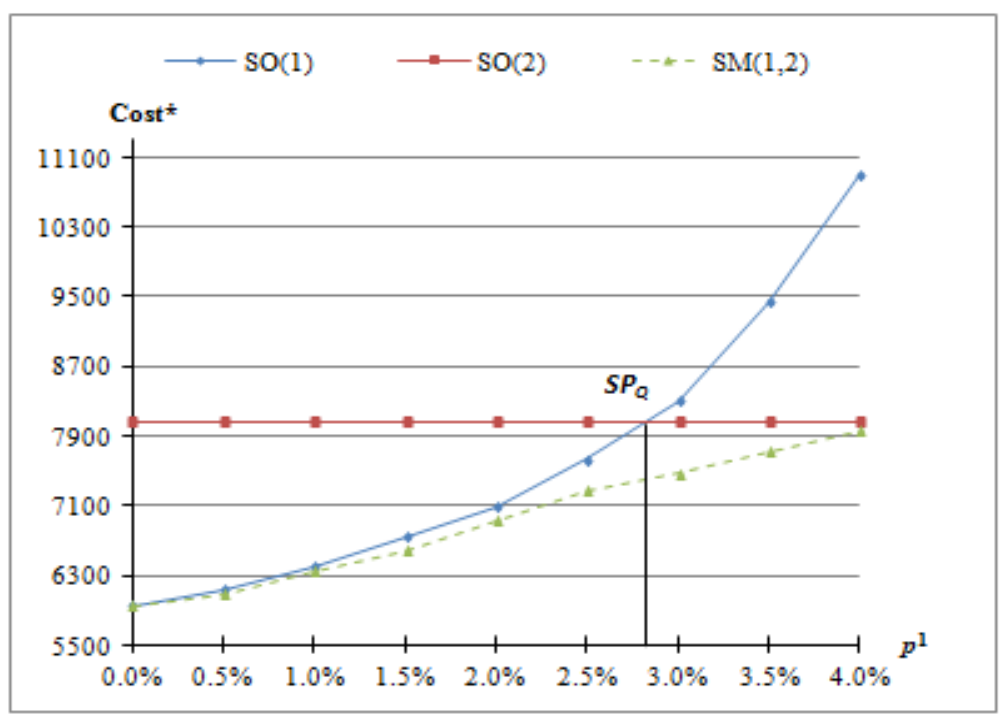

(a) $n=100$

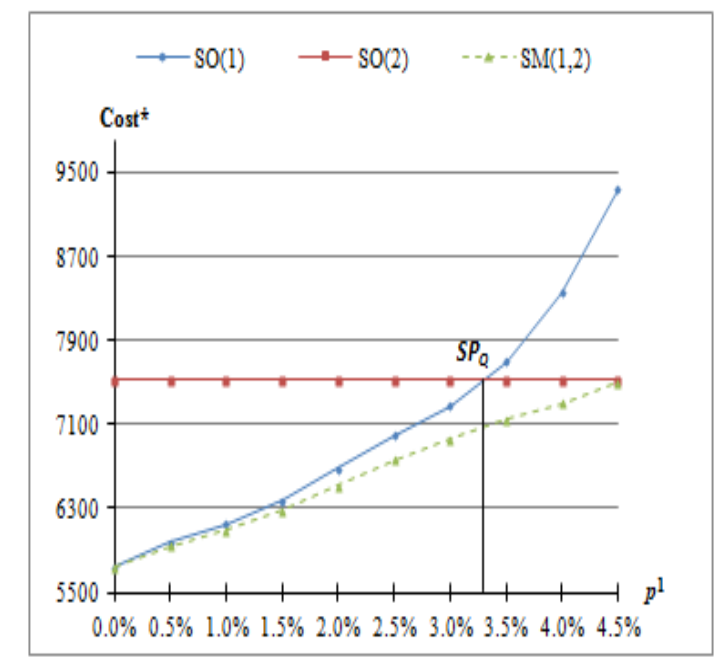

(b) $n=70$

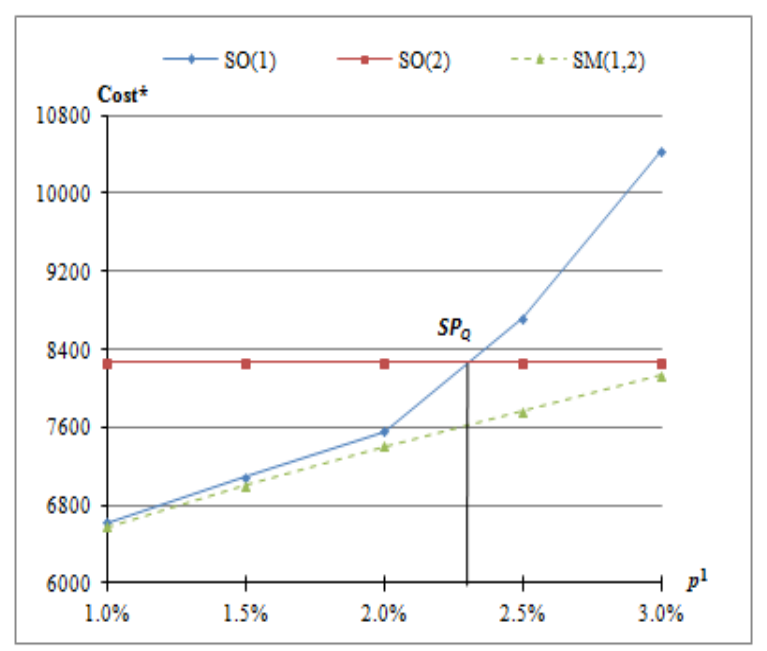

(c) $n=130$

Fig. 6. Variation of the optimal total cost depending on $p^{1}$ value $\left(\operatorname{Cost}^{*}=f\left(p^{1}\right)\right)$

\subsubsection{Effect of delay and cost variation}

From Fig. 7 (resp. Fig. 8), we note that when an SO policy is applied, the decision maker may select supplier 1 or supplier 2 , depending on the supply chain parameters. Fig. 7 (resp. Fig. 8) indeed shows the existence of a switching point $S P_{\delta}$ (resp. $S P_{C}$ ), which represents the maximum mean value of $\delta^{1}$ (resp. $C R^{1}$ ) for which supplier 1 is preferred. Exceeding this value, the decision maker must change his preference to supplier 2 . Regarding the choice of the supplier selection policy, Fig. 7 and Fig. 8 show that the $S M(1,2)$ policy is always preferred to the $S O$ policy decision $(S O(1)$ and $S O(2))$. 


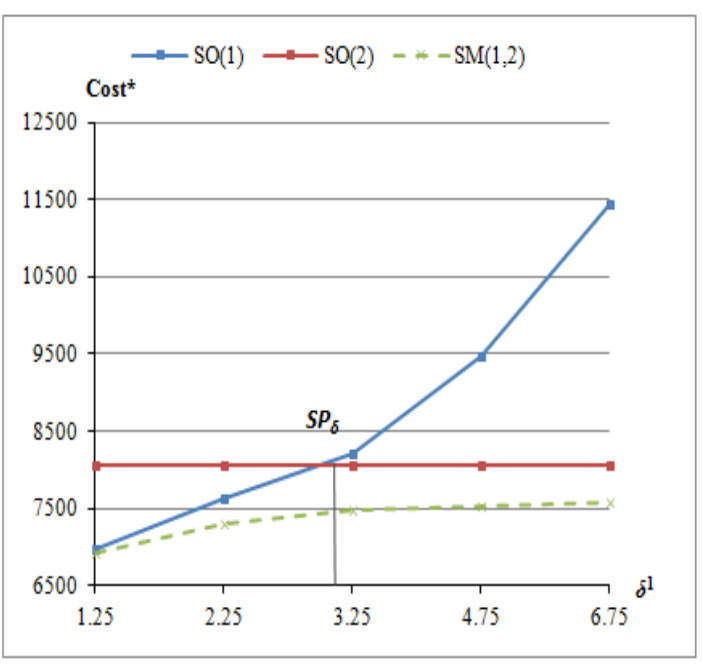

Fig. 7. Variation of the optimal total cost depending on $\delta^{1}$ value $\left(\right.$ Cost $\left.^{*}=\mathrm{f}\left(\delta^{1}\right)\right)$

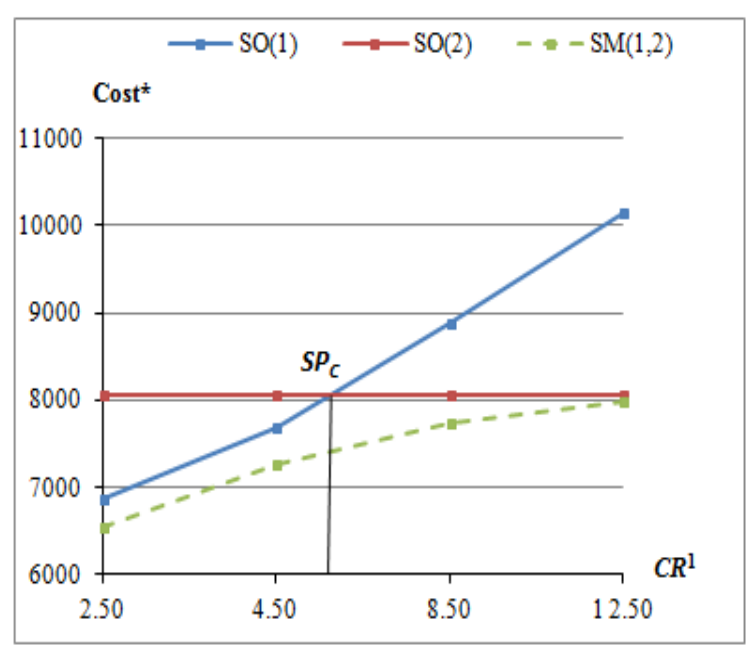

Fig. 8. Variation of the optimal total cost depending on $C R^{1}$ value $\left(\operatorname{Cost}^{*}=f\left(C R^{1}\right)\right)$

The results obtained clearly show that the incurred cost under $S M$ policy is better than that under $S O$ policy. We can conclude that when the supplier performance is variable, it is preferable to have significant choice flexibility while taking into consideration the overall situation of the supply chain. This result leads us to the following question: What will be the decision maker choice if the number of suppliers increases?

\subsection{Case of three Suppliers}

This section presents another set of experiments in which three suppliers are considered. As was the case for the two-supplier scenario, the three-supplier case includes suppliers 1 and 2 (Table 3 ) and supplier 3 (Table 6).

Table 6 Parameters of supplier 3

\begin{tabular}{|c|c|c|c|c|}
\hline Parameter & $\mathrm{W}^{3}$ & $\mathrm{CR}^{3}()$. & $\delta^{3}()$. & $p^{3}()$. \\
\hline Supplier 3 & 4000 & $U(4,13)$ & $U(1.2,2.8)$ & $U(0.5 \%, 2.5 \%)$ \\
\hline
\end{tabular}

Fig. 9, Fig. 10 and Fig. 11 illustrate the variations of the optimal total cost under the SO policy, the $S M$ (two suppliers) policy and the $S M$ (three suppliers) policy. Along the considered axis, $p^{1}, p^{2}$ or $p^{3}$, we set the parameters of two suppliers and vary the third one. An interesting point is that in all three figures, the optimal cost under the three supplier $\operatorname{SM}(1,2,3)$ policy is better than that under the two supplier $(\operatorname{SM}(1,2)$ policy, 
$S M(1,3)$ policy and $S M(2,3)$ policy) and the one supplier $(S O(1)$ policy, $S O(2)$ policy and $S O(3)$ policy).

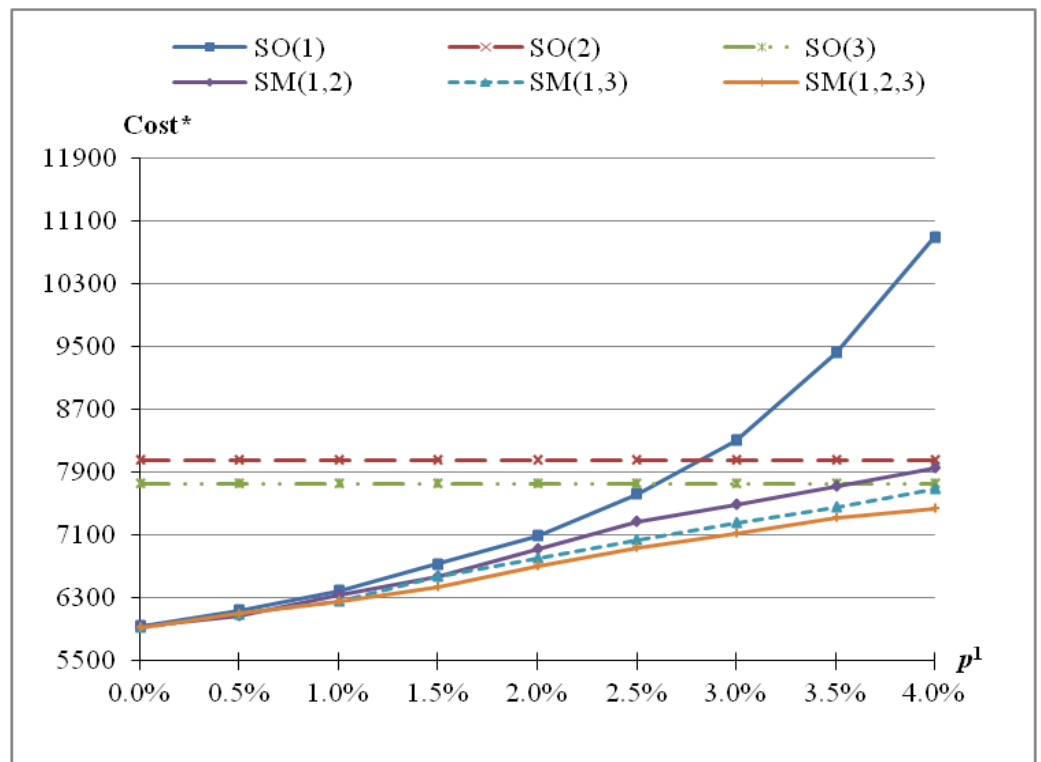

Fig. 9. Variation of the optimal total cost depending on $p^{1}$ value

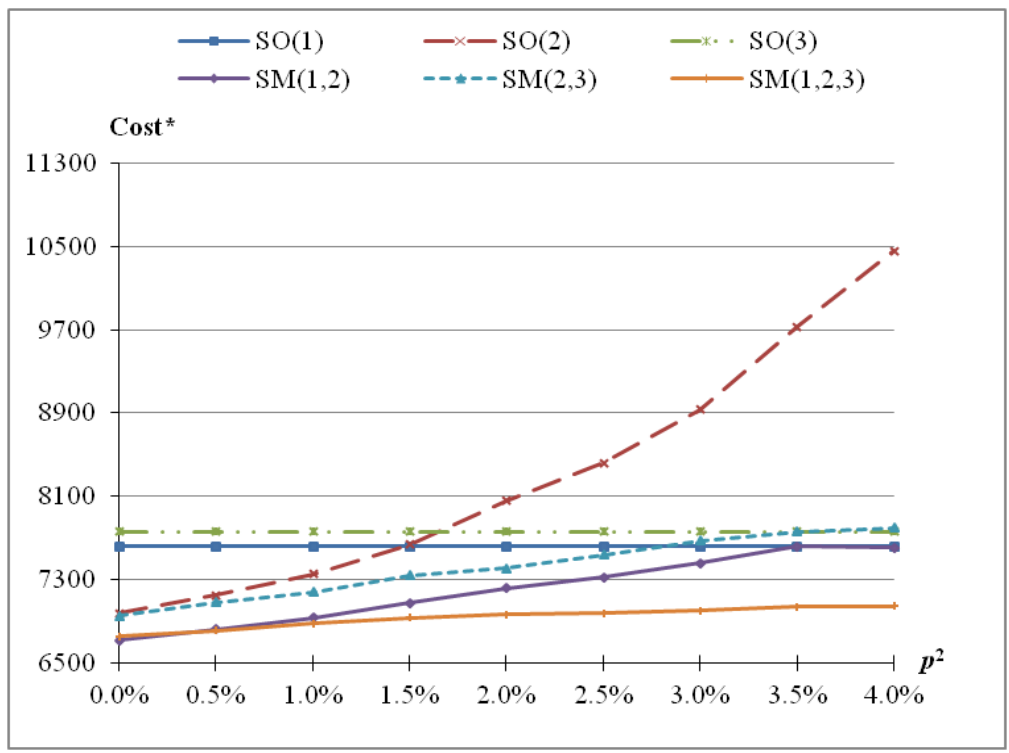

Fig. 10. Variation of the optimal total cost depending on $p^{2}$ value 


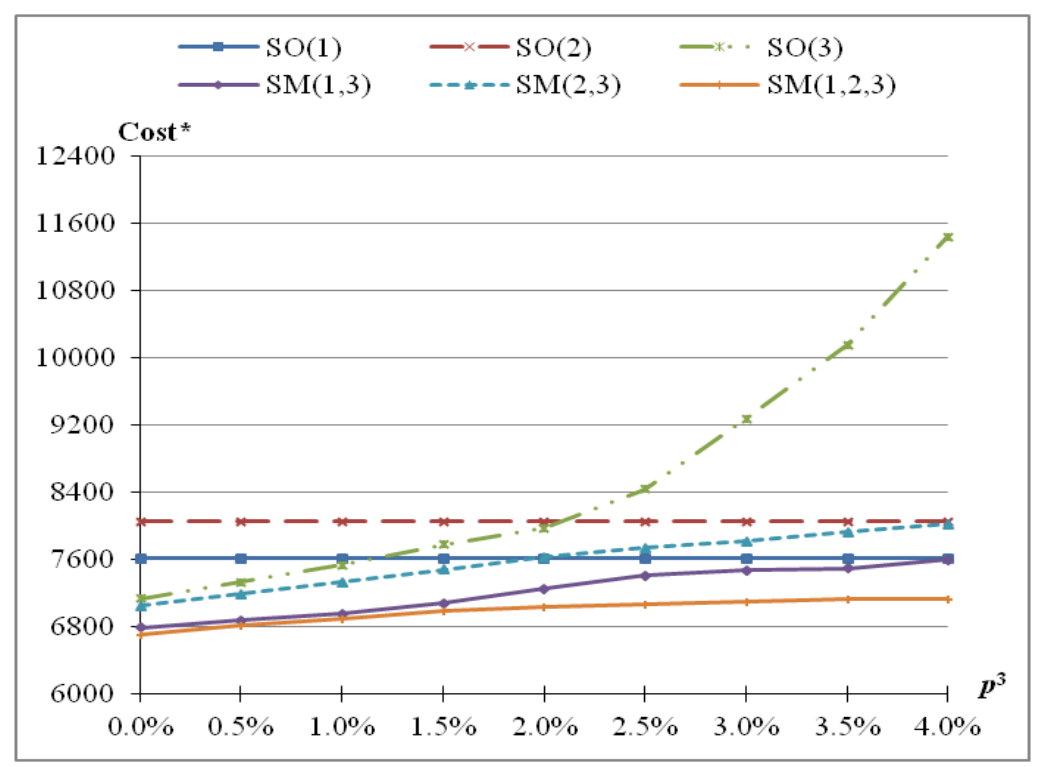

Fig. 11. Variation of the optimal total cost depending on $p^{3}$ value

9.3. Case of two-supplier, two-machine and four-product supply chain

In the previous sections, a three-stage supply chain involving multiple suppliers and a manufacturer producing one type of product that responds to a final customer with stable demand, is used in order to define, without loss of generality, the optimal replenishment, production, quality control and supplier selection policy, which is described though $S M$ and $S O$ policies. This supply chain is characterised by a manufacturing system with an exponential failure and repair time and a machine that does not produce non-conforming items.

In the control theory sphere, systems with multiple-machine producing multiple products (Gharbi and Kenne, 2003; Gharbi et al., 2006), with non-exponential machine up and down time (Gharbi et al., 2006; Kenné and Gharbi, 2000), with random demand (Kenné and Gharbi, 2000), and producing non-conforming parts (Rivera-Gómez et al., 2013) have been studied. Optimal control policies are obtained using a methodology based on simulation and statistical methods, such as experimental design and RSM methodology, even though doing so raises their complexity.

In this section, we will expand our considered system to the case of a manufacturing system with two different machines and four product types evolving in a three-stage supply chain involving two suppliers. The two suppliers are characterised by four 
parameters that follow a general probability distribution. The two machines are characterised by different production rates and non-exponential machine up and down times. Furthermore, each machine could produce a proportion of non-conforming products. The customer's demand rates follow general probability distributions. Here, the determination of the optimal parameters of the control policies ( $S M$ and $S O$ ) is possible thanks to our approach, which is based on a simulation model and an RSM methodology. The objective here is to confirm that our proposed supplier selection policy $(S M)$ is better than the classical one $(S O)$ for this complex system.

Table 7-9 present the data parameters of the three-stage supply chain under study.

Table 7 Suppliers' parameters

\begin{tabular}{|c|c|c|c|c|}
\hline Parameter & $W^{j}(\$)$ & $\mathrm{CR}^{\mathrm{j}}().(\$)$ & $\delta^{j}().($ time $)$ & $\mathrm{p}^{\mathrm{j}}()$. \\
\hline Supplier 1 & 4000 & $\mathrm{U}(2,7)$ & $\begin{array}{c}\text { Normal } \\
(2.25,0.2)\end{array}$ & $U(2.3 \%, 2.7 \%)$ \\
\hline Supplier 2 & 4000 & $\mathrm{U}(6,10)$ & $\begin{array}{c}\text { Normal } \\
(1.75,0.2)\end{array}$ & $\mathrm{U}(1.8 \%, 2.2 \%)$ \\
\hline
\end{tabular}

Table 8 Parameters of manufacturing system

\begin{tabular}{|c|c|c|c|c|c|c|c|c|}
\hline & & $\mathrm{Ma}$ & $\mathrm{mpr}$ & tion & & \multirow{3}{*}{$\mathrm{TTF}_{\mathrm{i}}$} & \multirow{3}{*}{$\mathrm{TTR}_{\mathrm{i}}$} & \multirow{3}{*}{$\operatorname{pProd}^{i}()}$. \\
\hline & & \multicolumn{4}{|c|}{ Product $P_{k}$} & & & \\
\hline & & $\mathrm{P}_{1}$ & $\mathrm{P}_{2}$ & $\mathrm{P}_{3}$ & $\mathrm{P}_{4}$ & & & \\
\hline \multirow{2}{*}{ 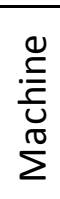 } & $\mathrm{M}_{1}$ & 270 & 275 & 285 & 290 & $\begin{array}{c}\text { Log-Normal } \\
(80,5)\end{array}$ & $\begin{array}{c}\text { Gamma } \\
(0.9,10)\end{array}$ & $\begin{array}{c}\text { Normal } \\
(1 \%, 0.1 \%)\end{array}$ \\
\hline & $\mathrm{M}_{2}$ & 210 & 205 & 195 & 190 & $\begin{array}{c}\text { Log-Normal } \\
(60,5)\end{array}$ & $\begin{array}{c}\text { Gamma } \\
(0.7,10)\end{array}$ & $\begin{array}{c}\text { Normal } \\
(0.75 \%, 0.1 \%)\end{array}$ \\
\hline
\end{tabular}

where $M_{\mathrm{i}}$ denotes the machine $i(i=1,2), P_{k}$ denotes the product of type $k(k=1,2,3,4)$, $T T F_{i}$ denotes the time-to-failure distribution of machine $M_{i}, T T R_{i}$ denotes the time-torepair distribution of machine $M_{i}$, and $\operatorname{pProd}^{i}($.$) denotes the percentage of non-$ conforming product items under machine $M_{i}$. 
Table 9 Parameters of customer demand rates

\begin{tabular}{ccccc}
\hline \multirow{2}{*}{ Parameter } & \multicolumn{4}{c}{ Product $P_{k}$} \\
\cline { 2 - 5 } & $P_{1}$ & $P_{2}$ & $P_{3}$ & $P_{4}$ \\
\hline \multirow{2}{*}{ Demand $\left(\right.$ Dem $\left._{k}\right)$} & Normal & Normal & Normal & Normal \\
& $(62,3)$ & $(93,3)$ & $(31,3)$ & $(124,3)$
\end{tabular}

where $\operatorname{Dem}_{k}$ denotes the finished product demand rate of product $P_{\mathrm{k}}, \mathrm{k}=1,2,3,4$.

Table 10 presents the optimal parameters and the minimum total cost, respectively, for the $S O(1), S O(2)$ and $S M(1,2)$ models. Based on these results, we note that the $S M(1,2)$ policy is the best one.

Table 10 Optimal variables and cost

\begin{tabular}{ccccc||c}
\hline \multirow{2}{*}{ Policies } & \multicolumn{4}{c||}{ Optimal variables } & Optimal cost \\
\cline { 2 - 5 } & $s^{*}$ & $Q^{*}$ & $Z_{P r}^{*}$ & $Z_{S}^{*}$ & Cost $^{*}$ \\
\hline$S O(1)$ & 980.03 & 3446 & 1332.67 & - & 8340.57 \\
$S O(2)$ & 689.82 & 3281 & 1030.46 & - & 9184.64 \\
$S M(1,2)$ & 900.09 & 3130 & 1192.76 & 6.92 & 8068.76
\end{tabular}

Additional experiments were conducted to determine the decision maker preference in terms of the best supplier selection policy. Fig. 12 shows the evolution of optimal costs for the two considered policies ( $S O$ and $S M$ ) for different values of $p^{1}$. It shows that the optimal costs under the $S M$ policy are always lower than those incurred under the $S O$ policy. Facing a high level of variation, the decision maker will prefer to have a flexible choice, while taking into consideration the overall situation of the supply chain. In fact, depending on the supplier parameters and the system state, the $S M$ policy always ensures the selection of the best offering supplier, which reduces the total cost. The same conclusions are obtained when varying other parameters, as in the previous sections. 


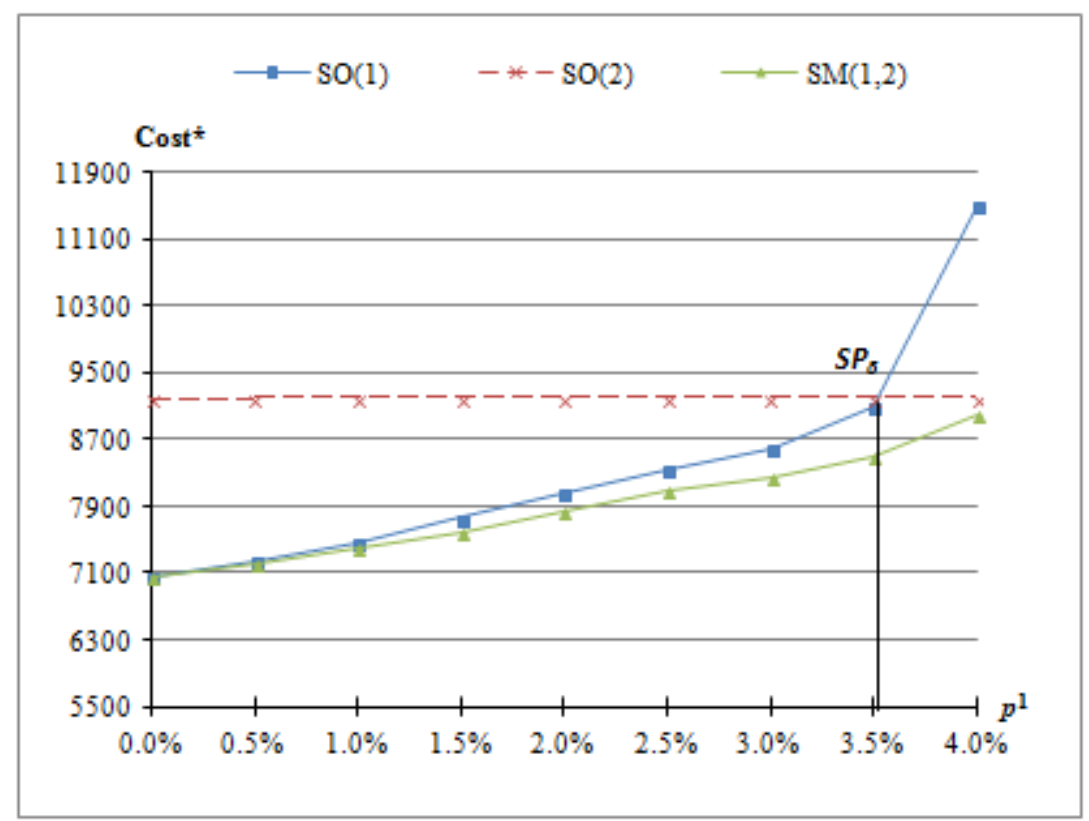

Fig. 12.Variation of optimal cost depending on $p^{1}$ value

Consequently, it can be concluded that the SM policy represents the better control policy for the integrated replenishment, production, quality control and supplier selection decisions.

\section{Policy implementation}

The practical implementation of the integrated policy proposed in this paper calls for complete information on the state variables of the manufacturing system and supplier parameters. In this context, the raw material $(x(t))$ and finished products $(y(t))$ stock levels, as well as the supplier parameters (proportion of non-conforming parts, replenishment delay and raw material cost) are required. The advantage of the proposed integrated control policy is that it allows decisions to be made on production, replenishment, quality control and supplier selection at any given time based on the whole system state and parameters. As an illustration, in Fig. 13, we present a logic chart that guides the decision making process. 


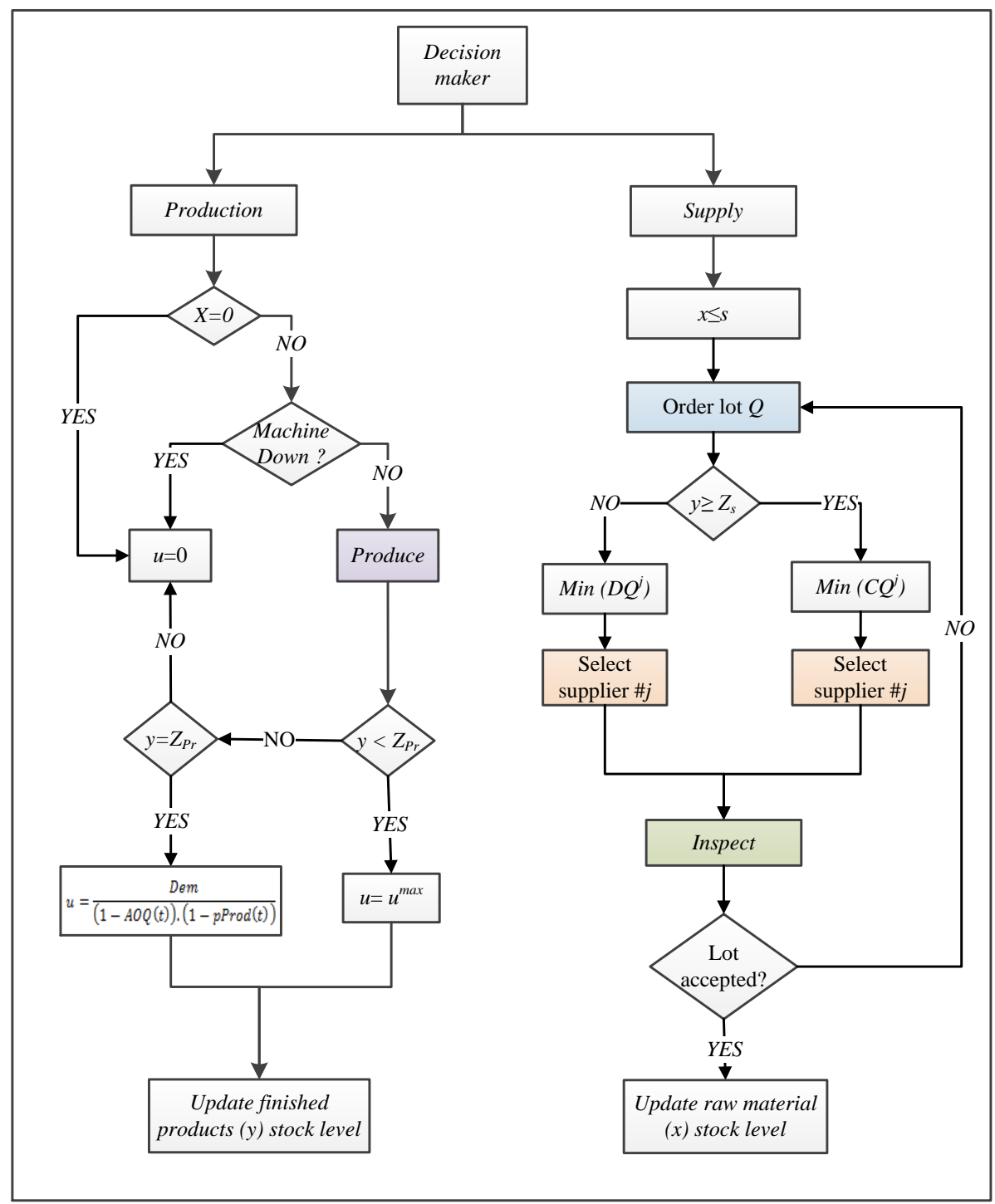

Fig. 13 Implementation logic chart of SM policy

\section{Conclusion}

In this paper, we have developed, in a stochastic and dynamic context, an integrated production, replenishment, supplier selection and raw material quality control policy to minimize the total cost of a manufacturing-oriented supply chain system under an unreliable transformation stage and stochastic supplier parameters.

A new supplier selection policy ( $S M$ policy) is proposed and compared to a classical selection decision (selecting and keeping the best supplier ( $S O$ policy)). This new policy is characterised by a flexible supplier selection decision depending on suppliers' 
parameters and the system parameters. To solve this problem and optimize the control parameters, a combination of analytical formulation, simulation modeling, statistical analysis and response surface methodology has been adopted.

Based on numerical examples, the results comparison between the different supplier selection policies confirm the significant cost savings that the proposed SM policy may ensure thanks to its dynamic nature. This new policy contributes to the supply chain management research in three ways. First, we have shown the effect of production policy on the supplier selection policy and how the coordination of integrated decisions increases the performance of the supply chain. Second, as the suppliers' performance is non-fixed over the time, it is preferable to have a significant choice flexibility while taking into consideration the overall parameters of the supply chain. Third, another notable advantage of this policy is how supplier diversity could improve the performance of the supply chain.

In this paper, we have assumed no cost to obtain and update the fluctuating information about cost, delay and quality from each supplier. If such a cost is considered, it will limit the number of suppliers to track. In this context, the optimal number of suppliers to consider could constitute an interesting extension to this paper. Moreover, this work can be extended further, considering the optimization of the sampling plan parameters or considering other kinds of sampling plan.

\section{Appendix A- Statistical analysis}

The independent variable levels are presented in Table A. 1. For each design, five replications were conducted. To ensure that the steady-state was reached, the duration of each simulation run was set to $T_{\infty}=500,000$ units of time. Furthermore, the common random number technique (Law, 2007) was used to reduce the variability from one configuration to another. 
Table A. 1 Level of independent variables

\begin{tabular}{cccc}
\hline Factors & Low Level & Center & High Level \\
\hline$S$ & 888 & 1050 & 1212 \\
$Q$ & 2344 & 3059 & 3774 \\
$Z_{P r}$ & 610 & 1250 & 1890 \\
$\beta=Z_{S} / Z_{P r}$ & 0 & 0.45 & 0.9
\end{tabular}

where $\beta=\mathrm{Z}_{\mathrm{S}} / Z_{P r}$ (with $\beta \leq 1$ to make sure that $Z_{S} \leq Z_{P r}$ ).

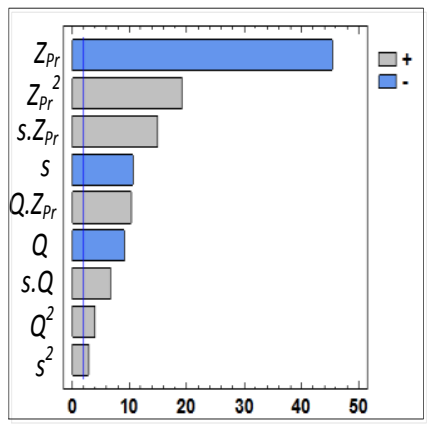

$\mathrm{R}_{\mathrm{ajs}}^{2}=95.76 \%$

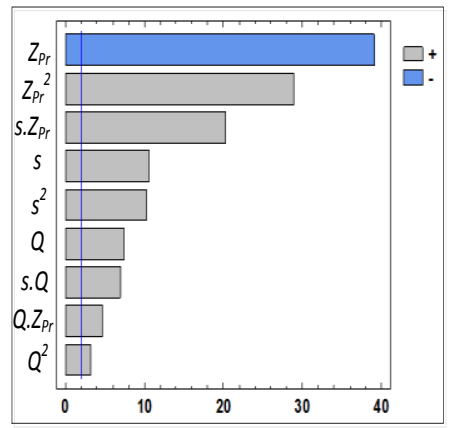

$\mathrm{R}_{\mathrm{ajs}}^{2}=95.89 \%$

(b) $S O(2)$ policy

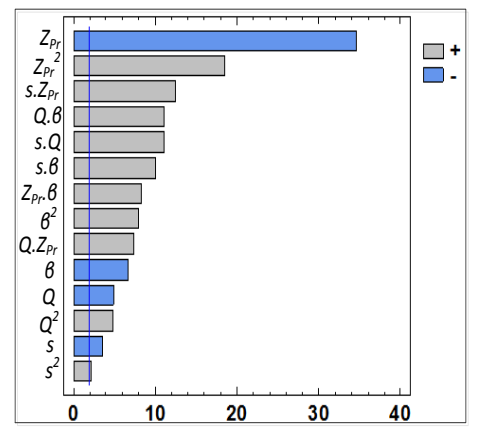

$\mathrm{R}_{\mathrm{ajs}}^{2}=97.37 \%$

(c) $\operatorname{SM}(1,2)$ policy

Fig. A. 1 Standardized Pareto plot for the total cost

Using a statistical software application such as STATGRAPHICS, we conducted a multifactor analysis of the variance (ANOVA) of the simulated data. This analysis provides the effects of the independent parameters on the dependent variable (the total incurred costs). Based on Fig. A. 1, the Pareto plot shows that all factors, their quadratic effect and their interaction, are significant for the response variable at the $95 \%$ level of significance. To check the suitability of the regression models obtained from this analysis, we went through two steps (Myers et al., 2009). The first step consists in evaluating the overall performance of the different models. The analysis of the adjusted R-squared $\left(R_{a d j}^{2}\right)$ shows that all the $R_{a d j}^{2}$ values (Fig. A. 1) of the proposed regression models are greater than $95 \%$. Then, over $95 \%$ of the total variability is explained by the models. Secondly, a residual analysis was conducted to verify the adequacy of the models. Residual versus predicted value plot and normal probability plot were analysed to confirm the homogeneity of the variances and the residual normality, respectively. 


\section{Acknowledgements}

This research has been supported by Natural Sciences and Engineering Research Council of Canada (NSERC) under grant number: RGPIN-2015-06026.

\section{References}

Aissaoui, N., Haouari, M., Hassini, E., 2007. Supplier selection and order lot sizing modeling: A review. Computers \& operations research 34, 3516-3540.

Amorim, P., Curcio, E., Almada-Lobo, B., Barbosa-Póvoa, A.P.F.D., Grossmann, I.E., 2016. Supplier selection in the processed food industry under uncertainty. European Journal of Operational Research 252, 801-814.

Bouslah, B., Gharbi, A., Pellerin, R., 2016a. Integrated production, sampling quality control and maintenance of deteriorating production systems with AOQL constraint. Omega 61, 110-126.

Bouslah, B., Gharbi, A., Pellerin, R., 2016b. Joint economic design of production, continuous sampling inspection and preventive maintenance of a deteriorating production system. International Journal of Production Economics 173, 184-198.

Burke, G.J., Carrillo, J.E., Vakharia, A.J., 2007. Single versus multiple supplier sourcing strategies. European journal of operational research 182, 95-112.

Burke, G.J., Carrillo, J.E., Vakharia, A.J., 2009. Sourcing decisions with stochastic supplier reliability and stochastic demand. Production and Operations Management $18,475-484$.

Chai, J.Y., Liu, J.N.K., Ngai, E.W.T., 2013. Application of decision-making techniques in supplier selection: A systematic review of literature. Expert Systems with Applications 40, 3872-3885.

Chan, F.T.S., Kumar, N., Tiwari, M.K., Lau, H.C.W., Choy, K.L., 2008. Global supplier selection: a fuzzy-AHP approach. International Journal of Production Research 46, 3825-3857.

Chen, X., Zhang, J., 2010. Production control and supplier selection under demand disruptions. Journal of Industrial Engineering and Management 3, 421-446.

Choudhary, D., Shankar, R., 2013. Joint decision of procurement lot-size, supplier selection, and carrier selection. Journal of Purchasing and Supply Management 19, 16-26.

Cohen, M.A., Agrawal, N., 1999. An analytical comparison of long and short term contracts. IIE transactions 31, 783-796.

Cui, L.X., 2014. Joint optimization of production planning and supplier selection incorporating customer flexibility: an improved genetic approach. Journal of Intelligent Manufacturing, 1-19.

Federgruen, A., Yang, N., 2014. Infinite horizon strategies for replenishment systems with a general pool of suppliers. Operations research 62, 141-159.

Firouz, M., Keskin, B.B., Melouk, S.H., 2016. An integrated supplier selection and inventory problem with multi-sourcing and lateral transshipments. Omega. 
Gharbi, A., Hajji, A., Dhouib, K., 2011. Production rate control of an unreliable manufacturing cell with adjustable capacity. International Journal of Production Research 49, 6539-6557.

Gharbi, A., Kenne, J.P., 2003. Optimal production control problem in stochastic multipleproduct multiple-machine manufacturing systems. IIE transactions 35, 941-952.

Gharbi, A., Kenné, J.P., Hajji, A., 2006. Operational level-based policies in production rate control of unreliable manufacturing systems with set-ups. International Journal of Production Research 44, 545-567.

Gorji, M.H., Setak, M., Karimi, H., 2014. Optimizing inventory decisions in a two-level supply chain with order quantity constraints. Applied Mathematical Modelling 38, 814-827.

Hajji, A., Gharbi, A., Kenné, J.P., Pellerin, R., 2011a. Production control and replenishment strategy with multiple suppliers. European Journal of Operational Research 208, 67-74.

Hajji, A., Gharbi, A., Rekik, M., 2011b. Decision support system for production and supplier selection in unreliable supply chains, International Conference on Industrial Engineering and Systems Management, Metz, France.

Hlioui, R., Gharbi, A., Hajji, A., 2015a. Integrated quality strategy in production and raw material replenishment in a manufacturing-oriented supply chain. Int $\mathbf{J}$ Adv Manuf Technol, 1-14.

Hlioui, R., Gharbi, A., Hajji, A., 2015b. Replenishment, production and quality control strategies in three-stage supply chain. International Journal of Production Economics 166, 90-102.

Ho, W., Xu, X., Dey, P.K., 2010. Multi-criteria decision making approaches for supplier evaluation and selection: A literature review. European Journal of Operational Research 202, 16-24.

Kenné, J.P., Gharbi, A., 2000. Production planning problem in manufacturing systems with general failure and repair time distributions. Production Planning \& Control 11, 581-588.

Keskin, B.B., Melouk, S.H., Meyer, I.L., 2010. A simulation-optimization approach for integrated sourcing and inventory decisions. Computers \& Operations Research 37, 1648-1661.

Lavoie, P., Gharbi, A., Kenné, J.P., 2010. A comparative study of pull control mechanisms for unreliable homogenous transfer lines. International Journal of Production Economics 124, 241-251.

Law, A.M., 2007. Simulation modeling and analysis, 4th ed.. ed. McGraw-Hill, Boston.

Liao, C.N., Kao, H.P., 2011. An integrated fuzzy TOPSIS and MCGP approach to supplier selection in supply chain management. Expert Systems with Applications 38, 10803-10811.

Lin, C.J., Kuo, H.H., 2014. Multiple Comparisons with the Best for Supplier Selection. Quality and Reliability Engineering International 30, 1083-1092.

Lin, C.T., Chen, C.B., Ting, Y.C., 2011. An ERP model for supplier selection in electronics industry. Expert Systems with Applications 38, 1760-1765.

Lin, Y.T., Lin, C.L., Yu, H.C., Tzeng, G.H., 2010. A novel hybrid MCDM approach for outsourcing vendor selection: A case study for a semiconductor company in Taiwan. Expert Systems with Applications 37, 4796-4804. 
Mahapatra, S., Bisi, A., Narasimhan, R., Levental, S., 2016. Integrated Contract and Spot Market Procurement by a Risk-Averse Buying Firm. IEEE Transactions on Engineering Management 63, 151-164.

Mendoza, A., Ventura, J.A., 2012. Analytical models for supplier selection and order quantity allocation. Applied Mathematical Modelling 36, 3826-3835.

Mitra, A., 2016. Fundamentals of quality control and improvement. John Wiley \& Sons.

Montgomery, D.C., 2013. Design and analysis of experiments, 8th ed.. ed. John Wiley \& Sons, Inc., Hoboken, NJ.

Myers, R.H., Montgomery, D.C., Anderson-Cook, C.M., 2009. Response surface methodology : process and product optimization using designed experiments, 3rd ed. ed. Wiley, Hoboken, N.J.

Naimi Sadigh, A., Fallah, H., Nahavandi, N., 2013. A multi-objective supply chain model integrated with location of distribution centers and supplier selection decisions. International Journal of Advanced Manufacturing Technology 69, 225-235.

Pazhani, S., Ventura, J.A., Mendoza, A., 2016. A serial inventory system with supplier selection and order quantity allocation considering transportation costs. Applied Mathematical Modelling 40, 612-634.

Pegden, C.D., 1995. Introduction to Simulation using SIMAN, 2nd ed. ed. McGraw-Hill, New York.

Peleg, B., Lee, H.L., Hausman, W.H., 2002. Short-term e-procurement strategies versus long-term contracts. Production and Operations Management 11, 458.

Pinedo, M., 2002. Scheduling : theory, algorithms, and systems, 2nd ed. ed. PrenticeHall, Upper Saddle River, N.J.

Rezaei, J., Davoodi, M., 2008. A deterministic, multi-item inventory model with supplier selection and imperfect quality. Applied Mathematical Modelling 32, 2106-2116.

Rivera-Gómez, H., Gharbi, A., Kenné, J.P., 2013. Joint production and major maintenance planning policy of a manufacturing system with deteriorating quality. International Journal of Production Economics 146, 575-587.

Ruiz-Torres, A.J., Mahmoodi, F., Zeng, A.Z., 2013. Supplier selection model with contingency planning for supplier failures. Computers \& Industrial Engineering 66, 374-382.

Sawik, T., 2014. Joint supplier selection and scheduling of customer orders under disruption risks: Single vs. dual sourcing. Omega 43, 83-95.

Sawik, T., 2016. Integrated supply, production and distribution scheduling under disruption risks. Omega 62, 131-144.

Schilling, E.G., Neubauer, D.V., 2009. Acceptance sampling in quality control, 2nd ed. ed. CRC Press, Boca Raton.

Sharma, S., Balan, S., 2013. An integrative supplier selection model using Taguchi loss function, TOPSIS and multi criteria goal programming. Journal of Intelligent Manufacturing 24, 1123-1130.

Song, D.P., Dong, J.X., Xu, J., 2014. Integrated inventory management and supplier base reduction in a supply chain with multiple uncertainties. European Journal of Operational Research 232, 522-536.

Tajbakhsh, M.M., Zolfaghari, S., Lee, C.-G., 2007. Supply uncertainty and diversification: a review, Trends in Supply Chain Design and Management. Springer, pp. 345-368. 
Tang, O., Musa, S.N., 2011. Identifying risk issues and research advancements in supply chain risk management. International Journal of Production Economics 133, 25-34.

Ventura, J.A., Valdebenito, V.A., Golany, B., 2013. A dynamic inventory model with supplier selection in a serial supply chain structure. European Journal of Operational Research 230, 258-271.

Ware, N.R., Singh, S.P., Banwet, D.K., 2014. A mixed-integer non-linear program to model dynamic supplier selection problem. Expert Systems with Applications 41, 671-678.

Weber, C.A., Current, J.R., 1993. A multiobjective approach to vendor selection. European Journal of Operational Research 68, 173-184.

Wu, T., Blackhurst, J., 2009. Supplier evaluation and selection: an augmented DEA approach. International Journal of Production Research 47, 4593-4608. 